\title{
Flexible manufacturing system selection using preference ranking methods : A comparative study
}

\author{
Prasenjit Chatterjee $^{a}$ and Shankar Chakraborty ${ }^{b^{*}}$
}

\begin{tabular}{l}
${ }^{a}$ Mechanical Engineering Department, \\
${ }^{b}$ Department of Production Engineerin \\
\hline C H R O N I C L E \\
\hline Article history: \\
Received July 22013 \\
Received in revised format \\
September 72013 \\
Accepted October 232013 \\
Available online \\
October 252013 \\
Keywords: \\
Flexible manufacturing system \\
Multi-criteria decision-making \\
Preference ranking method \\
Ranking
\end{tabular}

\section{Introduction}

In today's global competitive environment, manufacturing organizations need to be more flexible, adaptive and responsive to changes to produce a variety of products in a short time at the minimum cost. High competition, technological advancements and continuous change in customers' demands have made the manufacturing organizations realize the importance of manufacturing flexibility, which can only be achieved through the adoption and augmentation of flexible manufacturing systems (FMSs)

* Corresponding author.

E-mail: s_chakraborty00@yahoo.co.in (S. Chakraborty)

(C) 2014 Growing Science Ltd. All rights reserved.

doi: $10.5267 / j . i j i e c .2013 .10 .002$

\begin{abstract}
Flexible manufacturing systems (FMSs) offer opportunities for the manufacturers to improve their technology, competitiveness and profitability through a highly efficient and focused approach to manufacturing effectiveness. Justification, evaluation and selection of FMSs have now been receiving significant attention in the manufacturing environment. Evaluating alternative FMSs in the presence of multiple conflicting criteria and performance measures is often a difficult task for the decision maker. Preference ranking tools are special types of multicriteria decision-making methods in which the decision maker's preferences on criteria are aggregated together to arrive at the final evaluation and selection of the alternatives. This paper deals with the application of six most potential preference ranking methods for selecting the best FMS for a given manufacturing organization. It is observed that although the performances of these six methods are almost similar, ORESTE (Organization, Rangement Et Synthese De Donnes Relationnelles) method slightly outperforms the others. These methods use some preference function or utility value or Besson ranking of criteria and alternatives, to indicate how much an alternative is preferred to the others. Most of these methods need quantification of criteria weights or different preference parameters, but ORESTE method, being an ordinal outranking approach, only requires ordinal data and attribute rankings according to their importance. Therefore, it is particularly applicable to those situations where the decision maker is unable to provide crisp evaluation data and attribute weights.
\end{abstract}

(C) 2014 Growing Science Ltd. All rights reserved 
(O'Grady and Menon, 1986). The FMS has been a focal theme in the manufacturing related research since the early 1970s. A high level of flexibility can enable the manufacturing organizations to provide faster response to market changes, while maintaining increased product quality standards. The FMS can present opportunities for the manufacturing organizations to improve their technology, competitiveness and profitability through a highly efficient and focused approach to manufacturing effectiveness. However, implementation of FMS is extremely capital-intensive. Prior to its implementation, a careful analysis regarding its feasibility and performance is needed, in which the impact of various long- and medium-term managerial, social and economic factors associated with FMS adoption can be assessed.

An FMS consists of computerized numerical control machines and/or robots, physically linked by a conveyance network to move parts and/or tools, and an overall effective computer control to create an integrated system. The reason the FMS is called 'flexible' is that it is capable of processing a variety of different part styles simultaneously at various workstations, and the mix of part styles and production quantities can be easily adjusted in response to changing demand patterns. Potential benefits of an FMS implementation include reduced inventory levels, manufacturing lead times, floor space, and setup and labor costs, in addition to higher flexibility, quality, speed of response and a longer useful life of the equipment over successive generations of products. An FMS can manufacture a wide range of products in batch sizes from one to thousands. As an FMS implementation involves a huge capital investment, the selection of the most appropriate FMS from a set of candidate configurations requires extensive analysis and evaluation. Thus, the selection of an FMS requires trading off among various performance attributes of FMS alternatives so as to achieve the maximum possible benefits from its implementation. Among these attributes, some are quite difficult to quantify, some are conflicting in nature and some are to be balanced against each other while taking into account the preferences of the decision maker in the manufacturing organizations. High quality management is not enough for dealing with this type of complex and ill-structured decision-making problem. Hence, there is a need for simple mathematical tools to help the decision maker to select the most suitable FMS for a given industrial application.

As the evaluation and selection of the most appropriate FMS for an industrial application involves different conflicting criteria, it is a unique example where multi-criteria decision-making (MCDM) methods can be successfully applied. These FMS selection criteria can be categorized as objective and subjective attributes or beneficial and non-beneficial attributes. Objective attributes can be numerically defined, e.g. capital and maintenance cost of an FMS, floor space required for an FMS, reduction in work-in-process (WIP) etc. On the other hand, subjective attributes are qualitative in nature, like increase in market response, improvement in quality etc. Beneficial attributes are those whose higher values are desirable (reduction in WIP, improvement in quality etc.) and non-beneficial attributes are those whose lower values are always preferable (capital and maintenance cost of an FMS, floor space required for an FMS etc.).

The past researchers have already successfully applied different mathematical techniques, like analytic hierarchy process (Wabalackis, 1988; Chan et al., 2000; Bayazit, 2005), digraph and matrix approach (Rao, 2006; Rao and Parnichkun, 2009), compromise ranking method (Rao, 2009), artificial neural network (Bhattacharya et al., 2007), data envelopment analysis (Shang \& Sueyoshi, 1995; Sarkis, 1997; Talluri et al., 2000; Karsak, 2008; Liu, 2008), technique for order preference by similarity to ideal solution (TOPSIS) (Karsak, 2002; Rao, 2008), Euclidean distance-based integrated approach (Rao \& Singh, 2011), axiomatic design method (Kulak \& Kahraman, 2005), multi-objective programming method (Lotfi, 1995; Karsak \& Kuzgunkaya, 2002), fuzzy decision algorithm (Karsak, 2002; Karsak \& Tolga, 2001; Mehrabad \& Anvari, 2010), multi-attribute value function (Borenstein, 1998) etc. to solve the FMS selection problems. However, there is still a need to search for some more efficient and accurate methods that can give more precise ranking of FMS alternatives. Preference ranking-based methods are observed to have immense potential to deal with complex decision-making problems in conflicting situations. This paper mainly focuses on the applications of six preference ranking methods 
for effectively solving the FMS selection problems. The ranking performance of these six methods is also compared.

Section 2 of this paper deals with the detailed mathematical formulations of the six considered preference ranking methods. In Section 3, a real time FMS selection problem is solved using these preference ranking methods. A comparative performance study between these methods is shown in Section 4. The results and discussions are presented in Section 5. The applicability of these methods is provided in Section 6 and Section 7 concludes the paper.

\section{Preference ranking methods}

Preference ranking methods are special types of MCDM approaches in which the decision maker's preferences and preferences on criteria are aggregated together to reach the final evaluation and decision about the alternatives considering all the selection attributes. These methods require information on the preferences among the instances of an attribute and the preferences across the existing attributes. The decision maker may express or define a ranking for the attributes as importance/weights. In classical preference ranking methods, the decision maker judges two alternatives based on the notion that one alternative is preferred to another or the two alternatives are indifferent or the decision maker is unable to compare them. According to these cases, three binary relations are defined, i.e. a) the strict preference relation $(\mathrm{P}), \mathrm{b})$ the indifference relation $(\mathrm{I})$, and c) the incomparability relation (R). Thus, a preference structure on a set of alternatives (X) is defined as a triplet (P, I, J) of binary relation (Ovchinnikov \& Roubens, 1992).

In these methods, preferences are usually incorporated in the decision-making process by assigning a preference function. The starting point is the decision matrix, which presents the performance of each alternative with respect to each criterion. Using the data of the decision matrix, the alternatives are pairwise compared with respect to every single criterion, and the concordance and discordance indices are determined. The results are expressed by the preference functions, which are calculated for each pair of alternatives and can range from 0 to 1 . A 0 value signifies that there is no difference between the pair of alternatives, whereas, 1 denotes a big difference. Then an outranking degree is estimated by multiplying the preferences by the criteria's weights and adding the single values, and subsequently the global preferences are calculated.

Although there are several preference ranking methods, this paper mainly deals with the following six methods which have the potential to be popular, widely acceptable and accurate for giving more precise ranking of the candidate alternatives.

a) Evaluation of mixed data (EVAMIX) method,

b) Complex proportional assessment (COPRAS) method,

c) Extended PROMETHEE II (EXPROM2) method,

d) ORESTE (Organization, Rangement Et Synthese De Donnes Relationnelles) method,

e) Operational competitiveness rating analysis (OCRA) method, and

f) Additive ratio assessment (ARAS) method.

The computational details of these above-mentioned methods are presented as below.

\subsection{EVAMIX method}

The EVAMIX method was mainly established by Voogd in 1983, and later advocated by Martel and Matarazzo (Martel \& Matarazzo, 2005). It is based on the determination of the dominance score of an alternative on criterion-by-criterion basis. This method is especially designed to deal with the mixed (quantitative and qualitative) data. The main difference between EVAMIX and other MCDM methods is that it can treat the qualitative (ordinal) criteria and quantitative (cardinal) criteria separately. Both 
the ordinal and cardinal data are separately normalized in the range of 0 to 1 using a linear normalization procedure. In this method, the degree of pair-wise dominance for each pair of alternatives is calculated as the difference in score received by the higher performing alternative compared to the poorer performing alternative. The weighted sum of the dominance scores is then assigned to each alternative. The outcome of this aggregation procedure is similar to the outcome of the weighted sum method.

The EVAMIX method consists of the following procedural steps enlisted as below (Martel \& Matarazzo, 2005; Hajkowicz \& Higgins, 2008):

Step 1: In the decision matrix, at first, differentiate between the ordinal and cardinal criteria.

Step 2: For beneficial attributes (where higher values are desired), normalize the decision matrix using the following equation:

$r_{i j}=\left[x_{i j}-\min \left(x_{i j}\right)\right] /\left[\max \left(x_{i j}\right)-\min \left(x_{i j}\right)\right](i=1,2, \ldots, m ; j=1,2, \ldots, n)$

where $x_{i j}$ is the performance measure of $i^{\text {th }}$ alternative with respect to $j^{\text {th }}$ criterion and $r_{i j}$ is the normalized value of $x_{i j}$.

For non-beneficial attributes (where lower values are preferable), Eq. (1) can be rewritten as follows:

$r_{i j}=\left[\max \left(x_{i j}\right)-x_{i j}\right] /\left[\max \left(x_{i j}\right)-\min \left(x_{i j}\right)\right]$

Step 3: Calculate the evaluative differences of $i^{\text {th }}$ alternative on each ordinal and cardinal criteria with respect to other alternatives. This step involves the calculation of differences in criteria values between different alternatives pair-wise.

Step 4: Compute the dominance scores of each alternative pair, $\left(\mathrm{i}, \mathrm{i}^{\prime}\right)$ for all the ordinal and cardinal criteria using the following equations:

$\alpha_{\mathrm{ii}}=\left[\sum_{\mathrm{j} \in \mathrm{O}}\left\{\mathrm{w}_{\mathrm{j}} \operatorname{sgn}\left(\mathrm{r}_{\mathrm{ij}}-\mathrm{r}_{\mathrm{i}^{\prime} \mathrm{j}}\right)\right\}^{\mathrm{c}}\right]^{1 / \mathrm{c}}$,

where $\operatorname{sgn}\left(r_{i j}-r_{i^{\prime} j}\right)=\left\{\begin{array}{c}+1 \text { if } r_{i j}>r_{i^{\prime} j} \\ 0 \text { if } r_{i j}=r_{i^{\prime} j} \\ -1 \text { if } r_{i j}<r_{i^{\prime} j}\end{array}\right.$

$\gamma_{\mathrm{ii}^{\prime}}=\left[\sum_{\mathrm{j} \in \mathrm{C}}\left\{\mathrm{w}_{\mathrm{j}} \operatorname{sgn}\left(\mathrm{r}_{\mathrm{ij}}-\mathrm{r}_{\mathrm{i}^{\prime} \mathrm{j}}\right)\right\}^{\mathrm{c}}\right]^{1 / \mathrm{c}}$,

where the symbol $c$ is a scaling parameter, for which any arbitrary positive odd number, like $1,3,5, \ldots$ may be chosen, $O$ and $C$ are the sets of ordinal and cardinal criteria respectively, $\alpha_{\mathrm{it}}$ and $\gamma_{\mathrm{it}^{\prime}}$ are the dominance scores for alternative pair, $\left(i, i^{\prime}\right)$ with respect to ordinal and cardinal criteria respectively, and $w_{j}$ is the weight (relative importance) of $\mathrm{j}^{\text {th }}$ criterion.

Step 5: Calculate the standardized dominance scores.

Martel and Matarazzo (2005) proposed an additive interval method to derive the standardized ordinal dominance score $\left(\delta_{\mathrm{ii}^{\prime}}\right)$ and cardinal dominance score $\left(\mathrm{d}_{\mathrm{ii}}\right)$ for the alternative pair, $\left(i, i^{\prime}\right)$ as follows: 
Standardized ordinal dominance score $\left(\delta_{\mathrm{ii}^{\prime}}\right)=\frac{\left(\alpha_{\mathrm{ii}^{\prime}}-\alpha^{-}\right)}{\left(\alpha^{+}-\alpha^{-}\right)}$,

where $\alpha^{+}\left(\alpha^{-}\right)$is the highest (lowest) ordinal dominance score for the alternative pair, $\left(i, i^{\prime}\right)$.

Standardized cardinal dominance score $\left(\mathrm{d}_{\mathrm{ii}}\right)=\frac{\left(\gamma_{\mathrm{ii}}-\gamma^{-}\right)}{\left(\gamma^{+}-\gamma^{-}\right)}$,

where $\gamma^{+}\left(\gamma^{-}\right)$is the highest (lowest) cardinal dominance score for the alternative pair, $\left(i, i^{\prime}\right)$.

Step 6: Determine the overall dominance score.

The overall dominance score, $\left(\mathrm{D}_{\mathrm{ii}}\right)$ for each pair of alternatives, $\left(i, i^{\prime}\right)$ is calculated to measure the degree by which alternative $i$ dominates alternative $i^{\prime}$.

$\mathrm{D}_{\mathrm{ii}}=\mathrm{w}_{\mathrm{O}} \delta_{\mathrm{ii}^{\prime}}+\mathrm{w}_{\mathrm{C}} \mathrm{d}_{\mathrm{ii}^{\prime}}$,

where $w_{O}$ is the sum of the weights for the ordinal criteria $\left(\mathrm{w}_{\mathrm{o}}=\sum_{\mathrm{j}=0} \mathrm{w}_{\mathrm{j}}\right)$ and $\mathrm{w}_{\mathrm{C}}$ is the sum of the weights for the cardinal criteria $\left(\mathrm{w}_{\mathrm{C}}=\sum_{\mathrm{j} \in \mathrm{C}} \mathrm{w}_{\mathrm{j}}\right)$.

Step 7: Calculate the appraisal score.

Appraisal score $\left(\mathrm{S}_{\mathrm{i}}\right)=\sum_{\mathrm{i}^{\prime}}\left(\frac{\mathrm{D}_{\mathrm{i}^{\prime}}}{\mathrm{D}_{\mathrm{it}^{\prime}}}\right)^{-1}$

The appraisal score for $i^{\text {th }}$ alternative $\left(\mathrm{S}_{\mathrm{i}}\right)$ is computed which gives the final preference of the alternatives. Higher the appraisal score, better is the performance of the alternative.

\subsection{COPRAS method}

The COPRAS method assumes direct and proportional dependences of the significance and utility degree of the available alternatives under the presence of mutually conflicting criteria (Kaklauskas et al., 2006; Kaklauskas et al., 2007; Zavadskas et al., 2008). It takes into account the performance of the alternatives with respect to different criteria and also the corresponding criteria weights. This method selects the best decision considering both the ideal and the ideal-worst solutions. The COPRAS method which is used here for evaluating and selecting the alternative FMSs adopts a stepwise ranking and evaluating procedure of the alternatives in terms of their significance and utility degree. The steps of COPRAS method are presented as below:

Step 1: Normalize the decision matrix using linear normalization procedure (Kaklauskas et al., 2006).

Step 2: Determine the weighted normalized decision matrix, $D$.

$\mathrm{D}=\left[\mathrm{y}_{\mathrm{ij}}\right]_{\mathrm{mxn}}=\mathrm{r}_{\mathrm{ij}} \mathrm{xw}_{\mathrm{j}} \quad(\mathrm{i}=1,2, \ldots, \mathrm{m} ; \mathrm{j}=1,2, \ldots, \mathrm{n})$

The sum of dimensionless weighted normalized values of each criterion is always equal to the weight for that criterion.

$\sum_{\mathrm{i}=1}^{\mathrm{m}} \mathrm{y}_{\mathrm{ij}}=\mathrm{w}_{\mathrm{j}}$

Thus, it can be said that the weight, $w_{j}$ of $j^{\text {th }}$ criterion is proportionally distributed among all the alternatives according to their weighted normalized value, $y_{i j}$. 
Step 3: The sums of weighted normalized values are calculated for both beneficial and non-beneficial attributes using the following equations:

$$
\begin{aligned}
& \mathrm{S}_{+\mathrm{i}}=\sum_{\mathrm{j}=1}^{\mathrm{n}} \mathrm{y}_{+\mathrm{ij}} \\
& \mathrm{S}_{-\mathrm{i}}=\sum_{\mathrm{j}=1}^{\mathrm{n}} \mathrm{y}_{-\mathrm{ij}}
\end{aligned}
$$

where $y_{+i j}$ and $y_{-i j}$ are the weighted normalized values for the beneficial and non-beneficial attributes respectively.

The greater the value of $S_{+i}$, the better is the alternative; and the lower the value of $S_{-i}$, the better is the alternative. The $S_{+i}$ and $S_{-i}$ values express the degree of goals attained by each alternative. In any case, the sums of 'pluses' $S_{+i}$ and 'minuses' $S_{-i}$ of the alternatives are always respectively equal to the sums of weights for the beneficial and non-beneficial attributes as expressed by the following equations:

$$
\begin{aligned}
& \mathrm{S}_{+}=\sum_{\mathrm{i}=1}^{\mathrm{m}} \mathrm{S}_{+\mathrm{i}}=\sum_{\mathrm{i}=1}^{\mathrm{m}} \sum_{\mathrm{j}=1}^{\mathrm{n}} \mathrm{y}_{+\mathrm{ij}} \\
& \mathrm{S}_{-}=\sum_{\mathrm{i}=1}^{\mathrm{m}} \mathrm{S}_{-\mathrm{i}}=\sum_{\mathrm{i}=1}^{\mathrm{m}} \sum_{\mathrm{j}=1}^{\mathrm{n}} \mathrm{y}_{-\mathrm{ij}}
\end{aligned}
$$

Step 4: Determine the significances of the alternatives on the basis of defining the positive alternatives $S_{+i}$ and negative alternatives $S_{-i}$ characteristics.

Step 5: Determine the relative significances or priorities $\left(Q_{i}\right)$ of the alternatives.

$$
\mathrm{Q}_{\mathrm{i}}=\mathrm{S}_{+\mathrm{i}}+\frac{\mathrm{S}_{-\min } \sum_{\mathrm{i}=1}^{\mathrm{m}} \mathrm{S}_{-\mathrm{i}}}{\mathrm{S}_{-\mathrm{i}} \sum_{\mathrm{i}=1}^{\mathrm{m}}\left(\mathrm{S}_{-\min } / \mathrm{S}_{-\mathrm{i}}\right)} \quad(\mathrm{i}=1,2, \ldots, \mathrm{m})
$$

where $S_{-\min }$ is the minimum value of $S_{-i}$. The greater the value of $Q_{i}$, the higher is the priority of the alternative. The relative significance value of an alternative shows the degree of satisfaction attained by that alternative. The alternative with the highest relative significance value $\left(Q_{\max }\right)$ is the best choice among the candidate alternatives.

Step 6: Calculate the quantitative utility $\left(\mathrm{U}_{\mathrm{i}}\right)$ for $\mathrm{i}^{\text {th }}$ alternative. The degree of an alternative's utility which leads to a complete ranking of the candidate alternatives, is determined by comparing the priorities of all the alternatives with the most efficient one and can be denoted as below:

$$
\mathrm{U}_{\mathrm{i}}=\left[\frac{\mathrm{Q}_{\mathrm{i}}}{\mathrm{Q}_{\max }}\right] \times 100 \%,
$$

where $Q_{\max }$ is the maximum relative significance value. These utility values of the alternatives range from $0 \%$ to $100 \%$.

\subsection{EXPROM2 method}

The extended PROMETHEE II (EXPROM2) is basically a modified version of PROMETHEE II (preference ranking organization method for enrichment evaluation) method. In this method, the relative performance of one alternative over the other is defined by two preference indices. The first 
one is weak preference index based on the aggregated preference function considering the criteria weights as determined in PROMETHEE II method. The second one is strict preference index based on the notion of ideal and anti-ideal solutions. The ideal and anti-ideal values are directly derived from the decision matrix, and they reflect the extreme limits for a particular criterion. A total preference index is also computed by adding the strict and the weak preference indices, which gives an accurate measure of intensity of preference of one alternative over the other considering all the criteria.

The procedural steps of EXPROM2 method are given as below (Raju \& Kumar, 1999; Doumpos \& Zopounidis, 2004):

Step 1: Normalize the decision matrix.

Step 2: Calculate the evaluative differences of $i^{\text {th }}$ alternative with respect to other alternatives. This step involves the calculation of differences in criteria values $\left(d_{j}\right)$ between different alternatives pair-wise.

Step 3: Calculate the preference function, $\mathrm{P}_{\mathrm{j}}\left(\mathrm{i}, \mathrm{i}^{\prime}\right)$.

There are mainly six types of preference functions, e.g. usual criterion, U-shape criterion, V-shaped criterion, level criterion, V-shape with indifference criterion and Gaussian criterion. For usual criterion, which is the most simple one, the following preference function is adopted:

$$
\begin{aligned}
& P_{j}\left(i, i^{\prime}\right)=0 \text { if } r_{i j} \leq r_{i j} \\
& P_{j}\left(i, i^{\prime}\right)=\left(r_{i j}-r_{i j}\right) \text { if } r_{i j}>r_{i j}
\end{aligned}
$$

Step 4: Calculate the weak preference index taking into account the criteria weights.

$$
W P\left(i, i^{\prime}\right)=\left\lfloor\sum_{j=1}^{n} w_{j} \times P_{j}\left(i, i^{\prime}\right)\right\rfloor / \sum_{j=1}^{n} w_{j}
$$

Step 5: Define the strict preference function, $S P_{j}\left(i, i^{\prime}\right)$.

The strict preference function is based on the comparison of the difference values $\left(\mathrm{dm}_{\mathrm{j}}\right)$ with the range of values as defined by the evaluation of the whole set of alternatives for a criterion.

$$
\mathrm{SP}_{j}\left(\mathrm{i}, \mathrm{i}^{\prime}\right)=\left[\max \left(0, d_{j}-L_{j}\right)\right] /\left[d m_{j}-L_{j}\right]
$$

where $L_{j}=$ limit of preference ( 0 for usual criterion preference function, and indifference values for other five preference functions) and $\mathrm{dm}_{\mathrm{j}}=$ difference between the ideal and anti-ideal values of $\mathrm{j}^{\text {th }}$ criterion.

Step 6: Compute the strict preference index.

$$
\operatorname{SP}\left(i, i^{\prime}\right)=\left[\sum_{j=1}^{n} w_{j} x P_{j}\left(i, i^{\prime}\right)\right] / \sum_{j=1}^{n} w_{j}
$$

Step 7: Calculate the value of total preference index.

$$
\operatorname{TP}\left(i, i^{\prime}\right)=\operatorname{Min}\left[1, W P\left(i, i^{\prime}\right)+\operatorname{SP}\left(i, i^{\prime}\right)\right]
$$

Step 8: Determine the leaving and the entering outranking flows using the following equations: 
Leaving (positive) flow for $\mathrm{i}^{\text {th }}$ alternative, $\varphi^{+}(\mathrm{i})=\frac{1}{\mathrm{~m}-1} \sum_{\mathrm{i}^{\prime}=1}^{\mathrm{m}} \mathrm{TP}\left(\mathrm{i}, \mathrm{i}^{\prime}\right) \quad\left(i \neq \mathrm{i}^{\prime}\right)$

Entering (negative) flow for $i^{\text {th }}$ alternative, $\varphi^{-}(i)=\frac{1}{m-1} \sum_{i^{\prime}=1}^{m} \operatorname{TP}\left(i^{\prime}, i\right) \quad\left(i \neq i^{\prime}\right)$

where $\mathrm{m}$ is the number of alternatives.

The leaving flow expresses how much an alternative dominates the other alternatives, while the entering flow denotes how much an alternative is dominated by the other alternatives. Based on these flow values, EXPROM2 method can give the complete preorder of the candidate alternatives by using a net flow.

Step 6: Calculate the net outranking flow for each alternative.

$\varphi(\mathrm{i})=\varphi^{+}(\mathrm{i})-\varphi^{-}(\mathrm{i})$

Step 7: Determine the ranking of all the considered alternatives depending on the values of $\varphi(i)$. The higher the value of $\varphi(i)$, the better is the alternative.

\subsection{ORESTE method}

The ORESTE method is a compensatory preference ranking approach, as it uses the differences between the ranks of pairs of actions based on their evaluations (Roubens, 1982; Pastijn \& Leysen, 1989). In many real time decision-making situations having several quantitative as well as qualitative criteria, this method is particularly appropriate to support the conflicting decisions in absence of crisp numerical values and weights of the attributes.

The ORESTE method deals with the situation where an alternative $a_{i}(i=1,2, \ldots, m)$ is ranked according to criterion $c_{j}(j=1,2, \ldots, n)$, and the main objective is to find a global preference structure on a set of alternatives, which reflects the evaluation of alternatives on each criterion and the preference among the criteria (Pastijn \& Leysen, 1989). Since it only takes into account the ranking of alternatives and criteria, it is mainly suited to problems with ordinal data, but it can also be used for problems with cardinal or mixed data. The main advantage of this method is that as it uses only the ordinal ranking of criteria which avoids the occurrence of lengthy discussions among the decision makers to set weight importance of the attributes, it speeds up the decision-making process.

The steps of ORESTE method are presented as below (Teghem et al., 1989):

Step 1: From the decision matrix, determine the weak order of the criteria indicating their relative importance as follows:

$\mathrm{c}_{1} \mathrm{P} \mathrm{c}_{2} \mathrm{I} \mathrm{c}_{3} \mathrm{P} \mathrm{c}_{4} \ldots \ldots \ldots \mathrm{c}_{\mathrm{n}}$

This means $c_{1}$ is the most important and preferred criterion, while $c_{2}$ and $c_{3}$ are tied as the intermediate important criteria and $c_{4}$ is the least important criterion.

Step 2: Determine for each criterion a weak order of the alternatives similar to step (1).

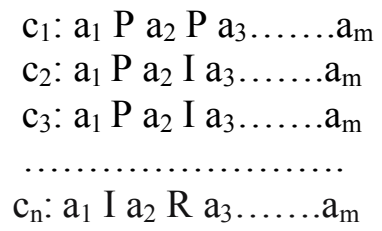


Step 3: Obtain Besson rankings of the alternatives and criteria.

In ORESTE method, each alternative is given a Besson rank based on its weak order among the other alternatives with respect to each criterion and also each criterion is given a Besson rank according to its position in the weak order among all the criteria. The Besson rank of an alternative $a_{i}$ with respect to a criterion $\mathrm{j}$ is denoted by $r_{j}\left(a_{i}\right)$ and the Besson rank of criterion $\mathrm{j}$ is denoted by $r c_{j}$.

Step 4: Calculate the projection distances.

The projection distances correspond to the relative positions of the alternatives with respect to an arbitrary origin $\mathrm{O}$ and are defined by $\mathrm{d}\left(\mathrm{O}, \mathrm{a}_{\mathrm{i}}\right)$.

Pastijn and Leysen (1989) discussed about different types of projections. In this paper, the linear orthogonal projection is adopted as expressed by the following equation

$d_{j}\left(O, a_{i}\right)=(1 / 2)\left[r c_{j}+r_{j}\left(a_{i}\right)\right]$.

Projection distances are such calculated that if an alternative $a_{1}$ is preferred to another alternative $a_{2}\left(a_{1}\right.$ $\left.P a_{2}\right)$ for criterion $j$, then $d_{j}\left(a_{1}\right)<d_{j}\left(a_{2}\right)$, i.e. the smaller projection distance, the better is the position of the alternative.

Step 5: Rank the projections to obtain the global ranks.

A mean global Besson rank $r_{j}\left(a_{i}\right)$ is assigned to all the projection distances from the lowest to the highest ones. Smaller $r_{j}\left(a_{i}\right)$ indicates better position of the particular alternative.

Step 6: Calculate the mean ranks.

For each alternative, a mean rank is computed by the summation of their global Besson ranks over the entire set of criteria using the following expression.

$r\left(a_{i}\right)=\sum_{j=1}^{n} r_{j}\left(a_{i}\right)$

These mean ranks are simply sorted increasingly to determine the global weak order of the alternatives.

\subsection{OCRA method}

The OCRA method was developed to measure the relative performance of a set of production units, where resources are consumed to create value-added outputs. In this method, in the first step, the preference ratings with respect to non-beneficial or input criteria are determined; in the second step, the preference ratings of the output criteria are determined, and in the last step, the overall preference ratings of the available alternatives are evaluated where both the cardinal and ordinal data are used. OCRA uses an intuitive method for incorporating the decision maker's preferences about the relative importance of the criteria (Parkan \& Wu, 1997; Parkan \& Wu, 1997). The preference ratings of the alternatives in OCRA method reflect the decision maker's preferences for the criteria. Besides this, the main advantage of OCRA method is that it can deal with those MCDM situations when the relative weights of the criteria are dependent on the alternatives and different weight distributions are assigned to the criteria for different alternatives as well as some of the criteria are not applicable to all the alternatives.

The general OCRA procedure is described as below (Parkan \& Wu, 2000):

Step 1: Compute the preference ratings with respect to the non-beneficial criteria.

In this step, OCRA method is only concerned with the scores that various alternatives receive for the input criteria without considering the scores received for the beneficial criteria. The lower values of 
non-beneficial or input criteria are more preferable. The aggregate performance of $i^{\text {th }}$ alternative with respect to all the input criteria is calculated using the following equation:

$\overline{I_{i}}=\sum_{j=1}^{n} w_{j} \frac{\max \left(x_{j}^{m}\right)-x_{j}^{i}}{\min \left(x_{j}^{m}\right)} \quad(i=1,2, \ldots, m ; j=1,2, \ldots, n ; i \neq m)$

where $\bar{I}_{i}$ is the measure of the relative performance of $i^{\text {th }}$ alternative and $x_{j}^{i}$ is the performance score of $\mathrm{i}^{\text {th }}$ alternative with respect to $\mathrm{j}^{\text {th }}$ input criterion. If $\mathrm{i}^{\text {th }}$ alternative is preferred to $\mathrm{m}^{\text {th }}$ alternative with respect to $j^{\text {th }}$ criterion, then $x_{j}^{i}<x_{j}^{m}$. The term $\frac{\max \left(x_{j}^{m}\right)-x_{j}^{i}}{\min \left(x_{j}^{m}\right)}$ indicates the difference in performance scores for criterion $\mathrm{j}$, between $\mathrm{i}^{\text {th }}$ alternative and the alternative whose score for criterion $\mathrm{j}$ is the highest among all the alternatives considered. The calibration constant $\mathrm{w}_{\mathrm{j}}$ (relative importance of $\mathrm{j}^{\text {th }}$ criterion) is used to increase or reduce the impact of this difference on the rating $\bar{I}_{i}$ with respect to $j^{\text {th }}$ criterion.

Step 2: Calculate the linear preference rating for the input criteria.

$\overline{\overline{\mathrm{I}_{\mathrm{i}}}}=\overline{\mathrm{I}_{\mathrm{i}}}-\min \left(\overline{\mathrm{I}}_{\mathrm{i}}\right)$.

This linear scaling is done to assign a zero rating to the least preferable alternative. $\overline{\overline{\mathrm{I}}}_{\mathrm{i}}$ represents the aggregate preference rating for $i^{\text {th }}$ alternative with respect to the input criteria.

Step 3: Compute the preference ratings with respect to the beneficial criteria.

The aggregate performance for $i^{\text {th }}$ alternative on all the beneficial or output criteria is measured using the following expression:

$\overline{\mathrm{O}_{\mathrm{i}}}=\sum_{\mathrm{h}=1}^{\mathrm{H}} \mathrm{w}_{\mathrm{h}} \frac{\mathrm{x}_{\mathrm{h}}^{\mathrm{i}}-\min \left(\mathrm{x}_{\mathrm{h}}^{\mathrm{m}}\right)}{\min \left(\mathrm{x}_{\mathrm{h}}^{\mathrm{m}}\right)}$,

where $h=1,2, \ldots, H$ indicates the number of beneficial criteria and $\mathrm{w}_{\mathrm{h}}$ is the calibration constant (weight importance) of $\mathrm{h}^{\text {th }}$ output criteria. The higher an alternative's score for an output criterion, the higher is the preference for that alternative.

It can be mentioned that $\sum_{j=1}^{n} w_{j}+\sum_{h=1}^{H} w_{h}=1$.

Step 4: Calculate the linear preference rating for the output criteria using the following equation:

$\overline{\overline{\mathrm{O}_{\mathrm{i}}}}=\overline{\mathrm{O}_{\mathrm{i}}}-\min \left(\overline{\mathrm{O}_{\mathrm{i}}}\right)$

Step 5: Compute the overall preference ratings.

The overall preference rating for each alternative is calculated by scaling the $\operatorname{sum}\left(\overline{\overline{\mathrm{I}_{i}}}+\overline{\overline{\mathrm{O}_{\mathrm{i}}}}\right)$ so that the least preferable alternative receives a rating of zero.

The overall preference rating $\left(\mathrm{P}_{\mathrm{i}}\right)$ is calculated as follows:

$\mathrm{P}_{\mathrm{i}}=\left(\overline{\overline{\mathrm{I}_{\mathrm{i}}}}+\overline{\overline{\mathrm{O}_{\mathrm{i}}}}\right)-\min \left(\overline{\overline{\mathrm{I}_{\mathrm{m}}}}+\overline{\overline{\mathrm{O}_{\mathrm{m}}}}\right)$

The alternatives are ranked according to the values of the overall preference rating. The alternative with the highest overall performance rating receives the first rank.

\subsection{ARAS method}


The ARAS method is based on quantitative measurements and utility theory. In this method, a utility function value determines the relative efficiency of an alternative over other alternatives. This utility function is directly proportional to the relative effect of the criteria values and weight importance of the considered criteria. The utility value of an alternative is determined by a comparison of variant with the ideally best alternative. The steps of ARAS method are as follows (Turskis \& Zavadskas, 2010; Zavadskas \& Turskis, 2010):

Step 1: For beneficial attributes, determine the normalized decision matrix, using linear normalization procedure (Zavadskas \& Turskis, 2010). For non-beneficial attributes, the normalization procedure follows two steps. At first, the reciprocal of each criterion with respect to all the alternatives is taken as follows:

$\mathrm{x}_{\mathrm{ij}}^{*}=\frac{1}{\mathrm{x}_{\mathrm{ij}}}$

In the second step, the normalized values are calculated as follows:

$$
\mathrm{R}=\left[\mathrm{r}_{\mathrm{ij}}\right]_{\mathrm{mxn}}=\frac{\mathrm{x}_{\mathrm{ij}}^{*}}{\sum_{\mathrm{i}=1}^{\mathrm{m}} \mathrm{x}_{\mathrm{ij}}^{*}}
$$

Step 2: Determine the weighted normalized decision matrix, D, using Eq. (9).

Step 3: Determine the optimality function $\left(\mathrm{S}_{\mathrm{i}}\right)$ for $i^{\text {th }}$ alternative.

$\mathrm{S}_{\mathrm{i}}=\sum_{\mathrm{j}=1}^{\mathrm{n}} \mathrm{y}_{\mathrm{ij}}$

Higher the $S_{i}$ value, the better is the alternative. The optimality function $S_{i}$ has a direct and proportional relationship with values in the decision matrix and criteria weights.

Step 4: Calculate the degree of the utility $\left(\mathrm{U}_{\mathrm{i}}\right)$ for each alternative.

It is determined by a comparison of the variant with the most efficient one $\left(\mathrm{S}_{0}\right)$. The equation used for calculating the value of $\mathrm{U}_{\mathrm{i}}$ is given as below:

$\mathrm{U}_{\mathrm{i}}=\frac{\mathrm{S}_{\mathrm{i}}}{\mathrm{S}_{0}}$

The utility values of the alternatives range from $0 \%$ to $100 \%$. The alternative with the highest utility value is the best choice among the candidate alternatives.

In some preference ranking methods, pair-wise comparison of the alternatives is performed to compute a preference function for each criterion and based on this preference function, a preference index is determined to show the preference of an alternative over the other. This preference index is the measure to support the hypothesis that there is some preference of an alternative over the other. In some other preference ranking methods, a utility or priority function value determines the relative efficiency of an alternative over the other. In all these approaches, the ranking index is nothing but an aggregation of the normalized criteria values, the relative importance of the criteria, and a balance between total and individual satisfaction or preference either by defining a preference function or an utility value. So basically, all the preference ranking methods whether it uses preference function or weighted sum utility value, indicate how much an alternative is preferred to the other.

\section{Industrial example}

Today's global competition has compelled the manufacturing organizations to improve their product quality in a cost effective manner. Use of proper manufacturing technologies, like FMS, offers great potentials for improving manufacturing performance and helps to attain the organizational objectives in an efficient way. A wrong alternative selection may result in loss of productivity and profitability. The 
complexity of decision-making makes multi-criteria analysis an invaluable tool in the engineering design and selection process. Thus, the main objective of this paper is set to reveal the computational easiness of the six preference ranking methods in dealing with FMS selection problems, involving both ordinal and cardinal attribute data. It mainly focuses on introducing these multi-beneficial MCDM methods that can make FMS selection easier and compatible with most of the situations. These preference ranking methods are applied to an existing problem, dealing with the selection of the best FMS alternative for a given manufacturing environment. In these methods, the decision makers' preferences and preferences on alternatives' performances are aggregated together to reach the final evaluation and selection decision. The past researchers have adopted different mathematical tools for evaluating, justifying and selecting FMS technologies, but all those methods are either very complicated or require lengthy computations. For decision-making problems with large number of attributes and small number of alternatives, those approaches may occasionally provide poor results. This paper takes the opportunity to explore the application viability and potentiality of six popular preference ranking methods to provide more precise and accurate ranking of the feasible FMS alternatives. According to the best knowledge of the authors, there have been very few applications of these preference ranking methods in manufacturing environment. Few successful implementations of these methods can be found in construction engineering, financial analysis and waste water management. Even till date, very less effort has been devoted to study the relative performance of these methods as employed in discrete manufacturing environment. Furthermore, no attempt has been made to map/match any FMS selection problem to these methods. All these methods are successfully applied and the results are compared for better visualization. Four performance analysis tests are also executed to assess the degree of agreement between the ranking orders as obtained by these methods, while keeping the performance measures in the evaluation matrix of the considered example constant. These six preference ranking methods are also qualitatively compared in terms of their suitability for solving different FMS selection problems, operational similarities and other model characteristics, like information type and criteria requirement, methodological aspect, operational approach, compensatory character and nature of the obtained results.

Thus, in order to apply these six preference ranking methods and compare their relative ranking performance, the FMS selection problem as considered by Karsak (2002) is cited here. Karsak (2002) considered eight alternative FMSs and eight attributes affecting the FMS selection decision for a given industrial application. Based on several literatures on evaluation and justification of FMS investments, Karsak (Karsak, 2002) considered capital and operating costs (COS), required floor space (RFS), work in progress (WIP), product flexibility (PF), volume flexibility (VF), expansion flexibility (EF), lead time reduction (LTR), and quality improvement (QI) as the main selection criteria for the considered problem. Product flexibility was defined as the ability to start producing a new set of part types quickly and economically. Volume flexibility was the ability to operate an FMS profitably at varying production levels, whereas, expansion flexibility was defined as the ability to easily add capability and capacity to an existing system. Among these, three attributes are quantitative in nature and the remaining five are judged in an interval of $0-1$ scale.

Karsak (2002) solved that FMS selection problem using a distance-based fuzzy TOPSIS method and obtained a comparative ranking of FMS alternatives as 6-2-1-7-5-8-4-3, which indicates that the first FMS alternative attains a rank of 6 , the second one has a rank of 2 , the third one achieves a rank of 1 , and so on. More precisely, the ranking order of FMS alternatives as obtained by Karsak (2002) is FMS3 $>$ FMS2 $>$ FMS8 $>$ FMS7 $>$ FMS5 $>$ FMS1 $>$ FMS4 $>$ FMS6. Table 1 represents the performance characteristics of the considered FMS alternatives with respect to all the criteria. Here, COS, RFS and WIP are non-beneficial attributes where lower values are always desirable. The weight values or relative importance of the eight criteria are determined using entropy method, as given in Table 2. 
Table 1

Quantitative data for the FMS selection problem (Karsak, 2002)

\begin{tabular}{|c|c|c|c|c|c|c|c|c|}
\hline FMS & $\begin{array}{l}\text { Capital and operating } \\
\text { costs (\$ millions) }\end{array}$ & $\begin{array}{l}\text { Required floor } \\
\text { space }\left(\mathrm{m}^{2}\right)\end{array}$ & $\begin{array}{c}\text { Work in } \\
\text { progress (units) }\end{array}$ & $\begin{array}{l}\text { Product } \\
\text { flexibility }\end{array}$ & $\begin{array}{l}\text { Volume } \\
\text { flexibility }\end{array}$ & $\begin{array}{l}\text { Expansion } \\
\text { flexibility }\end{array}$ & $\begin{array}{l}\text { Lead time } \\
\text { reduction }\end{array}$ & $\begin{array}{c}\text { Quality } \\
\text { improvement }\end{array}$ \\
\hline 1 & 3.8 & 630 & 42 & 0.7 & 0.5 & 0.7 & 0.5 & 0.2 \\
\hline 2 & 3.1 & 620 & 37 & 0.7 & 0.7 & 0.5 & 0.9 & 0.5 \\
\hline 3 & 5 & 425 & 32 & 0.9 & 0.7 & 0.7 & 0.7 & 0.7 \\
\hline 4 & 6.4 & 500 & 54 & 0.7 & 0.5 & 0.5 & 0.7 & 0.9 \\
\hline 5 & 3.6 & 600 & 44 & 0.2 & 0.7 & 0.7 & 0.2 & 0.7 \\
\hline 6 & 6.7 & 780 & 59 & 0.9 & 0.9 & 0.5 & 0.5 & 0.5 \\
\hline 7 & 3.4 & 740 & 37 & 0.5 & 0.2 & 0.2 & 0.7 & 0.9 \\
\hline 8 & 3.7 & 550 & 36 & 0.5 & 0.9 & 0.9 & 0.5 & 0.5 \\
\hline
\end{tabular}

Table 2

Criteria weights determined using entropy method

\begin{tabular}{ccccccccc} 
Criteria & COS & RFS & WIP & PF & VF & EF & LTR & QI \\
Weight & 0.1297 & 0.1420 & 0.1400 & 0.1173 & 0.1173 & 0.1194 & 0.1194 & 0.1150 \\
\hline
\end{tabular}

\subsection{EVAMIX method}

Now, this FMS selection problem is solved using EVAMIX method. In the original decision matrix, as shown in Table 1, the ordinal and cardinal criteria are at first separated (PF, VF, EF, LTR and QI are the qualitative attributes) and then, the decision matrix is normalized using Eq. (1) and Eq. (2) respectively for beneficial and non-beneficial attributes. This normalized decision matrix is shown in Table 3. From the normalized decision matrix, the evaluative differences of $i^{\text {th }}$ alternative for each ordinal and cardinal criteria with respect to all other alternatives are calculated. Now, the dominance scores of each pair of FMS alternatives for all the ordinal and cardinal criteria are estimated applying Eq. (3) and Eq. (4) respectively, and are given in Table 4. While calculating the dominance scores, the value of $\mathrm{c}$ is taken as 1 . Table 4 also exhibits the standardized dominance scores for all the pairs of FMS alternatives, as computed employing Eq. (5) and Eq. (6) respectively for the ordinal and cardinal criteria. The overall dominance score for each FMS alternative pair, (i,i') is calculated using Eq. (7) which shows the degree by which FMS i dominates FMS i'. These overall dominance scores for all the pairs of FMS alternatives are given in Table 5. Now, using Eq. (8), the appraisal score for each FMS alternative is calculated, as shown in Table 6 and based on the descending values of this appraisal score, the final ranking of FMS alternatives is obtained as 8-3-1-5-4-6-7-2. The best choice is FMS 3 . FMS 8 is the second choice and the last choice is FMS 1 .

Table 3

Normalized decision matrix for the FMS selection problem

\begin{tabular}{ccccccccc}
\hline FMS & COS & RFS & WIP & PF & VF & EF & LTR & QI \\
\hline 1 & 0.8056 & 0.4225 & 0.6296 & 0.7143 & 0.4286 & 0.7143 & 0.4286 & 0 \\
2 & 1 & 0.4507 & 0.8148 & 0.7143 & 0.7143 & 0.4286 & 1 & 0.4286 \\
3 & 0.4722 & 1 & 1 & 1 & 0.7143 & 0.7143 & 0.7143 & 0.7143 \\
4 & 0.0833 & 0.7887 & 0.1852 & 0.7143 & 0.4286 & 0.4286 & 0.7143 & 1 \\
5 & 0.8611 & 0.5070 & 0.5556 & 0 & 0.7143 & 0.7143 & 0 & 0.7143 \\
6 & 0 & 0 & 0 & 1 & 1 & 0.4286 & 0.4286 & 0.4286 \\
7 & 0.9167 & 0.1127 & 0.8148 & 0.4286 & 0 & 0 & 0.7143 & 1 \\
8 & 0.8333 & 0.6479 & 0.8519 & 0.4286 & 1 & 1 & 0.4286 & 0.4286 \\
\hline
\end{tabular}


Table 4

Dominance and standardized dominance scores of each alternative FMS pair

\begin{tabular}{|c|c|c|c|c|c|c|c|c|c|}
\hline $\begin{array}{l}\text { FMS } \\
\text { pair }\end{array}$ & $\alpha_{\mathrm{ii}^{\prime}}$ & $\gamma_{i^{\prime}}$ & $\delta_{\mathrm{ii}}$ & $\mathrm{d}_{\mathrm{ii}{ }^{\prime}}$ & $\begin{array}{l}\text { FMS } \\
\text { pair }\end{array}$ & $\alpha_{i^{\prime}}$ & $\gamma_{\mathrm{ii}^{\prime}}$ & $\delta_{\mathrm{ii}}$ & $\mathrm{d}_{\mathrm{ii}^{\prime}}$ \\
\hline$(1,2)$ & -0.2323 & -0.4116 & 0.1611 & 0 & $(5,1)$ & -0.0043 & 0.1317 & 0.3163 & 0.3849 \\
\hline$(1,3)$ & -0.4690 & -0.1522 & 0 & 0.1838 & $(5,2)$ & -0.0022 & -0.1276 & 0.3177 & 0.2012 \\
\hline$(1,4)$ & -0.1150 & 0.1276 & 0.2409 & 0.3821 & $(5,3)$ & -0.2366 & -0.1522 & 0.1581 & 0.1838 \\
\hline$(1,5)$ & 0.0043 & -0.1317 & 0.3222 & 0.1983 & $(5,4)$ & -0.1150 & 0.1276 & 0.2409 & 0.3821 \\
\hline$(1,6)$ & -0.2302 & 0.4116 & 0.1625 & 0.5832 & $(5,6)$ & -0.1195 & 0.4116 & 0.2379 & 0.5832 \\
\hline$(1,7)$ & 0.1195 & -0.1276 & 0.4006 & 0.2012 & $(5,7)$ & -0.1150 & -0.1276 & 0.2409 & 0.2012 \\
\hline$(1,8)$ & 1 & 1 & 1 & 1 & $(5,8)$ & 1 & 1 & 1 & 1 \\
\hline$(2,1)$ & 0.2323 & 0.4116 & 0.4774 & 0.5832 & $(6,1)$ & 0.2302 & -0.4116 & 0.4759 & 0 \\
\hline$(2,3)$ & -0.2323 & -0.1522 & 0.1611 & 0.1838 & $(6,2)$ & 0.1151 & -0.4116 & 0.3976 & 0 \\
\hline$(2,4)$ & 0.1216 & 0.1276 & 0.4020 & 0.3821 & $(6,3)$ & -0.2366 & -0.4116 & 0.1582 & 0 \\
\hline$(2,5)$ & 0.0022 & 0.1276 & 0.3208 & 0.3821 & $(6,4)$ & 0.0001 & -0.4116 & 0.3193 & 0 \\
\hline$(2,6)$ & -0.1151 & 0.4116 & 0.2409 & 0.5832 & $(6,5)$ & 0.1195 & -0.4116 & 0.4006 & 0 \\
\hline$(2,7)$ & 0.3582 & 0.2717 & 0.5631 & 0.4841 & $(6,7)$ & 0.1195 & -0.4116 & 0.4006 & 0 \\
\hline$(2,8)$ & 0 & -0.1522 & 0.3192 & 0.1838 & $(6,8)$ & 1 & 1 & 1 & 1 \\
\hline$(3,1)$ & 0.4690 & 0.1522 & 0.6385 & 0.3995 & $(7,1)$ & -0.1195 & 0.1276 & 0.2379 & 0.3821 \\
\hline$(3,2)$ & 0.2323 & 0.1522 & 0.4774 & 0.3995 & $(7,2)$ & -0.3582 & -0.2717 & 0.0754 & 0.0991 \\
\hline$(3,4)$ & 0.2389 & 0.4116 & 0.4818 & 0.5832 & $(7,3)$ & -0.2389 & -0.1522 & 0.1566 & 0.1838 \\
\hline$(3,5)$ & 0.2366 & 0.1522 & 0.4803 & 0.3995 & $(7,4)$ & -0.3539 & 0.1276 & 0.0783 & 0.3821 \\
\hline$(3,6)$ & 0.2366 & 0.4116 & 0.4803 & 0.5832 & $(7,5)$ & 0.1150 & 0.1276 & 0.3976 & 0.3821 \\
\hline$(3,7)$ & 0.2389 & 0.1522 & 0.4818 & 0.3995 & $(7,6)$ & -0.1195 & 0.4116 & 0.2379 & 0.5832 \\
\hline$(3,8)$ & 1 & 1 & 1 & 1 & $(7,8)$ & -0.0022 & -0.1522 & 0.3177 & 0.1838 \\
\hline$(4,1)$ & 0.1150 & $(4,1)$ & 0.3976 & 0.2012 & $(8,1)$ & 0.2344 & 0.4116 & 0.4788 & 0.5832 \\
\hline$(4,2)$ & -0.1216 & $(4,2)$ & 0.2365 & 0.2012 & $(8,2)$ & 0 & 0.1522 & 0.3192 & 0.3995 \\
\hline$(4,3)$ & -0.2389 & $(4,3)$ & 0.1566 & 0 & $(8,3)$ & -0.1150 & -0.1522 & 0.2409 & 0.1838 \\
\hline$(4,5)$ & 0.1150 & $(4,5)$ & 0.3976 & 0.2012 & $(8,4)$ & -0.1150 & 0.1276 & 0.2409 & 0.3821 \\
\hline$(4,6)$ & -0.0001 & $(4,6)$ & 0.3192 & 0.5832 & $(8,5)$ & 0.3582 & 0.1522 & 0.5631 & 0.3995 \\
\hline$(4,7)$ & 0.3539 & $(4,7)$ & 0.5602 & 0.2012 & $(8,6)$ & 0.0021 & 0.4116 & 0.3207 & 0.5832 \\
\hline$(4,8)$ & 1 & $(4,8)$ & 1 & 1 & $(8,7)$ & 0.0022 & 0.1522 & 0.3208 & 0.3995 \\
\hline
\end{tabular}

Table 5

Overall dominance scores for EVAMIX method

\begin{tabular}{cccccccc}
\hline FMS pair & $\mathrm{D}_{\mathrm{ii}^{\prime}}$ & FMS pair & $\mathrm{D}_{\mathrm{ii}}$ & FMS pair & $\mathrm{D}_{\mathrm{ii}^{\prime}}$ & FMS pair & $\mathrm{D}_{\mathrm{ii}^{\prime}}$ \\
\hline$(1,2)$ & 0.0948 & $(3,1)$ & 0.5401 & $(5,1)$ & 0.3445 & $(7,1)$ & 0.2973 \\
$(1,3)$ & 0.0757 & $(3,2)$ & 0.4453 & $(5,2)$ & 0.2697 & $(7,2)$ & 0.0852 \\
$(1,4)$ & 0.2990 & $(3,4)$ & 0.5236 & $(5,3)$ & 0.1687 & $(7,3)$ & 0.1678 \\
$(1,5)$ & 0.2712 & $(3,5)$ & 0.4470 & $(5,4)$ & 0.2990 & $(7,4)$ & 0.2034 \\
$(1,6)$ & 0.3357 & $(3,6)$ & 0.5227 & $(5,6)$ & 0.3801 & $(7,5)$ & 0.3912 \\
$(1,7)$ & 0.3185 & $(3,7)$ & 0.4479 & $(5,7)$ & 0.2246 & $(7,6)$ & 0.3801 \\
$(1,8)$ & 1 & $(3,8)$ & 1 & $(5,8)$ & 1 & $(7,8)$ & 0.2626 \\
$(2,1)$ & 0.5210 & $(4,1)$ & 0.3167 & $(6,1)$ & 0.2800 & $(8,1)$ & 0.5218 \\
$(2,3)$ & 0.1704 & $(4,2)$ & 0.2219 & $(6,2)$ & 0.2339 & $(8,2)$ & 0.3523 \\
$(2,4)$ & 0.3938 & $(4,3)$ & 0.0922 & $(6,3)$ & 0.0931 & $(8,3)$ & 0.2174 \\
$(2,5)$ & 0.3460 & $(4,5)$ & 0.3167 & $(6,4)$ & 0.1879 & $(8,4)$ & 0.2990 \\
$(2,6)$ & 0.3818 & $(4,6)$ & 0.4279 & $(6,5)$ & 0.2357 & $(8,5)$ & 0.4957 \\
$(2,7)$ & 0.5306 & $(4,7)$ & 0.4124 & $(6,7)$ & 0.2357 & $(8,6)$ & 0.4288 \\
$(2,8)$ & 0.2635 & $(4,8)$ & 1 & $(6,8)$ & 1 & $(8,7)$ & 0.3532 \\
\hline
\end{tabular}


Table 6

Appraisal score and rank of each alternative FMS in EVAMIX method

\begin{tabular}{ccccccccc}
\hline FMS & 1 & 2 & 3 & 4 & 5 & 6 & 7 & 8 \\
\hline $\mathrm{S}_{\mathrm{i}}$ & 0.0323 & 0.0689 & 0.1565 & 0.0489 & 0.0589 & 0.0379 & 0.0357 & 0.0776 \\
Rank & 8 & 3 & 1 & 5 & 4 & 6 & 7 & 2 \\
\hline
\end{tabular}

\subsection{COPRAS method}

In this method, using Eq. (9), the corresponding weighted normalized decision matrix is developed, as given in Table 7. Now, based on Eq. (11) and Eq. (12), the sums of the weighted normalized values are calculated for both the beneficial attributes $\left(\mathrm{S}_{+\mathrm{i}}\right)$ and non-beneficial attributes $\left(\mathrm{S}_{-\mathrm{i}}\right)$, as shown in Table 8 . Then, applying Eq. (15), the relative significance or priority value $\left(\mathrm{Q}_{\mathrm{i}}\right)$ for each FMS alternative is computed, as given in Table 9. This table also exhibits the quantitative utility $\left(\mathrm{U}_{\mathrm{i}}\right)$ for each alternative on the basis of which the complete ranking of the FMS alternatives is obtained as 5-3-1-4-7-6-8-2. FMS 3 and FMS 8 obtain the first and second ranks respectively. FMS 7 is the last choice.

Table 7

Weighted normalized decision matrix for COPRAS method

\begin{tabular}{ccccccccc}
\hline FMS & COS & RFS & WIP & PF & VF & EF & LTR & QI \\
\hline 1 & 0.0138 & 0.0185 & 0.0172 & 0.0161 & 0.0115 & 0.0178 & 0.0127 & 0.0047 \\
2 & 0.0113 & 0.0182 & 0.0152 & 0.0161 & 0.0161 & 0.0127 & 0.0229 & 0.0117 \\
3 & 0.0182 & 0.0125 & 0.0131 & 0.0207 & 0.0161 & 0.0178 & 0.0178 & 0.0164 \\
4 & 0.0233 & 0.0147 & 0.0222 & 0.0161 & 0.0115 & 0.0127 & 0.0178 & 0.0211 \\
5 & 0.0131 & 0.0176 & 0.0181 & 0.0046 & 0.0161 & 0.0178 & 0.0051 & 0.0164 \\
6 & 0.0243 & 0.0229 & 0.0242 & 0.0207 & 0.0207 & 0.0127 & 0.0127 & 0.0117 \\
7 & 0.0124 & 0.0217 & 0.0152 & 0.0115 & 0.0046 & 0.0051 & 0.0178 & 0.0211 \\
8 & 0.0134 & 0.0161 & 0.0148 & 0.0115 & 0.0207 & 0.0229 & 0.0127 & 0.0117 \\
\hline
\end{tabular}

Table 8

Sums of the weighted normalized values for COPRAS method

\begin{tabular}{ccccc}
\hline FMS & $\mathrm{S}_{+\mathrm{i}}$ & Value & $\mathrm{S}_{-\mathrm{i}}$ & Value \\
\hline 1 & $\mathrm{~S}_{+1}$ & 0.0628 & $\mathrm{~S}_{-1}$ & 0.0495 \\
2 & $\mathrm{~S}_{+2}$ & 0.0795 & $\mathrm{~S}_{-2}$ & 0.0446 \\
3 & $\mathrm{~S}_{+3}$ & $\mathrm{~S}_{-3}$ & 0.0438 \\
4 & $\mathrm{~S}_{+4}$ & 0.0888 & $\mathrm{~S}_{-4}$ & 0.0601 \\
5 & $\mathrm{~S}_{+5}$ & 0.0792 & $\mathrm{~S}_{-5}$ & 0.0487 \\
6 & $\mathrm{~S}_{+6}$ & 0.0600 & $\mathrm{~S}_{-6}$ & 0.0714 \\
8 & $\mathrm{~S}_{+7}$ & 0.0785 & $\mathrm{~S}_{-7}$ & 0.0492 \\
\hline
\end{tabular}

\section{Table 9}

$\mathrm{Q}_{\mathrm{i}}$ and $\mathrm{U}_{\mathrm{i}}$ values in COPRAS method

\begin{tabular}{cccc}
\hline FMS & $\mathrm{Q}_{\mathrm{i}}$ & $\mathrm{U}_{\mathrm{i}}$ & Rank \\
\hline 1 & 0.1149 & 77.7559 & 5 \\
2 & 0.1373 & 92.9376 & 3 \\
3 & 0.1478 & 100.0000 & 1 \\
4 & 0.1222 & 82.6750 & 4 \\
5 & 0.1130 & 76.4438 & 7 \\
6 & 0.1147 & 77.5975 & 6 \\
7 & 0.1125 & 76.1433 & 8 \\
8 & 0.1377 & 93.1865 & 2 \\
\hline
\end{tabular}




\subsection{EXPROM2 method}

From the normalized decision matrix of Table 3 and employing Eq. (17) or Eq. (18), the corresponding preference functions are computed for all the pairs of FMS alternatives. Table 10 shows the weak preference index, strong preference index and total preference index for the alternative FMS pairs. As in this calculation, usual criterion is adopted as the preference function, both the values of weak and strong preference indices are obtained to be the same. Now, based on the leaving and entering outranking flows, as given in Table 11, the corresponding net outranking flow values are determined for all the alternatives. After arranging these net outranking flows in descending order, the final ranking of FMS alternatives is obtained, as shown in Table 11. The ranking of FMS alternatives is observed as 5-3-1-4-6-8-7-2 which signifies that FMS 3 is the best choice. FMS 8 obtains the second rank and FMS 6 is the worst choice.

Table 10

Weak, strong and total preference index values for alternative FMS pairs

\begin{tabular}{|c|c|c|c|c|c|c|c|}
\hline FMS pair & $\mathrm{WP}\left(\mathrm{i}, \mathrm{i}^{\prime}\right)$ & $\mathrm{SP}\left(\mathrm{i}, \mathrm{i}^{\prime}\right)$ & $\mathrm{TP}\left(\mathrm{i}, \mathrm{i}^{\prime}\right)$ & FMS pair & $\mathrm{WP}\left(\mathrm{i}, \mathrm{i}^{\prime}\right)$ & $\mathrm{SP}\left(\mathrm{i}, \mathrm{i}^{\prime}\right)$ & $\mathrm{TP}\left(\mathrm{i}, \mathrm{i}^{\prime}\right)$ \\
\hline$(1,2)$ & 0.0341 & 0.0341 & 0.0682 & $(5,1)$ & 0.1349 & 0.1349 & 0.2698 \\
\hline$(1,3)$ & 0.0432 & 0.0432 & 0.0865 & $(5,2)$ & 0.0750 & 0.0750 & 0.1500 \\
\hline$(1,4)$ & 0.1900 & 0.1900 & 0.3800 & $(5,3)$ & 0.0504 & 0.0504 & 0.1009 \\
\hline$(1,5)$ & 0.1453 & 0.1453 & 0.2906 & $(5,4)$ & 0.2203 & 0.2203 & 0.4407 \\
\hline$(1,6)$ & 0.2867 & 0.2867 & 0.5734 & $(5,6)$ & 0.3284 & 0.3284 & 0.6569 \\
\hline$(1,7)$ & 0.2130 & 0.2130 & 0.4261 & $(5,7)$ & 0.2250 & 0.2250 & 0.4501 \\
\hline$(1,8)$ & 0.0335 & 0.0335 & 0.0670 & $(5,8)$ & 0.0365 & 0.0365 & 0.0729 \\
\hline$(2,1)$ & 0.2062 & 0.2062 & 0.4123 & $(6,1)$ & 0.1498 & 0.1498 & 0.2996 \\
\hline$(2,3)$ & 0.1026 & 0.1026 & 0.2051 & $(6,2)$ & 0.0670 & 0.0670 & 0.1340 \\
\hline$(2,4)$ & 0.2746 & 0.2746 & 0.5493 & $(6,3)$ & 0.0335 & 0.0335 & 0.0670 \\
\hline$(2,5)$ & 0.2574 & 0.2574 & 0.5149 & $(6,4)$ & 0.1005 & 0.1005 & 0.2010 \\
\hline$(2,6)$ & 0.3760 & 0.3760 & 0.7519 & $(6,5)$ & 0.2019 & 0.2019 & 0.4039 \\
\hline$(2,7)$ & 0.2613 & 0.2613 & 0.5227 & $(6,7)$ & 0.2354 & 0.2354 & 0.4709 \\
\hline$(2,8)$ & 0.1233 & 0.1233 & 0.2467 & $(6,8)$ & 0.0670 & 0.0670 & 0.1340 \\
\hline$(3,1)$ & 0.3171 & 0.3171 & 0.6342 & $(7,1)$ & 0.1895 & 0.1895 & 0.3790 \\
\hline$(3,2)$ & 0.2044 & 0.2044 & 0.4088 & $(7,2)$ & 0.0657 & 0.0657 & 0.1315 \\
\hline$(3,4)$ & 0.2956 & 0.2956 & 0.5912 & $(7,3)$ & 0.0905 & 0.0905 & 0.1810 \\
\hline$(3,5)$ & 0.3347 & 0.3347 & 0.6695 & $(7,4)$ & 0.1962 & 0.1962 & 0.3924 \\
\hline$(3,6)$ & 0.4443 & 0.4443 & 0.8886 & $(7,5)$ & 0.2119 & 0.2119 & 0.4238 \\
\hline$(3,7)$ & 0.3879 & 0.3879 & 0.7759 & $(7,6)$ & 0.3488 & 0.3488 & 0.6976 \\
\hline$(3,8)$ & 0.2047 & 0.2047 & 0.4094 & $(7,8)$ & 0.1107 & 0.1107 & 0.2213 \\
\hline$(4,1)$ & 0.2012 & 0.2012 & 0.4023 & $(8,1)$ & 0.2171 & 0.2171 & 0.4343 \\
\hline$(4,2)$ & 0.1137 & 0.1137 & 0.2275 & $(8,2)$ & 0.1349 & 0.1349 & 0.2698 \\
\hline$(4,3)$ & 0.0329 & 0.0329 & 0.0657 & $(8,3)$ & 0.1145 & 0.1145 & 0.2289 \\
\hline$(4,5)$ & 0.2419 & 0.2419 & 0.4838 & $(8,4)$ & 0.3258 & 0.3258 & 0.6516 \\
\hline$(4,6)$ & 0.2486 & 0.2486 & 0.4971 & $(8,5)$ & 0.2305 & 0.2305 & 0.4610 \\
\hline$(4,7)$ & 0.2309 & 0.2309 & 0.4618 & $(8,6)$ & 0.3875 & 0.3875 & 0.7751 \\
\hline$(4,8)$ & 0.1534 & 0.1534 & 0.3067 & $(8,7)$ & 0.3178 & 0.3178 & 0.6356 \\
\hline
\end{tabular}

Table 11

Leaving flow, entering flow and net outranking flow values in EXPROM2 method

\begin{tabular}{ccccc}
\hline FMS & $\varphi^{+}(\mathrm{i})$ & $\varphi^{-}(\mathrm{i})$ & $\varphi(\mathrm{i})$ & $\mathrm{Rank}$ \\
\hline 1 & 0.2703 & 0.4045 & -0.1342 & 5 \\
2 & 0.4576 & 0.1985 & 0.2590 & 3 \\
3 & 0.6254 & 0.1336 & 0.4918 & 1 \\
4 & 0.3493 & 0.4580 & -0.1088 & 4 \\
5 & 0.3059 & 0.4639 & -0.1580 & 6 \\
6 & 0.2443 & 0.6915 & -0.4472 & 8 \\
7 & 0.3467 & 0.5347 & -0.1881 & 7 \\
8 & 0.4938 & 0.2083 & 0.2855 & 2 \\
\hline
\end{tabular}




\subsection{ORESTE method}

In this method, at first, the weak order of the criteria is determined indicating their relative importance. Based on the criteria values, as shown in Table 2, the weak order of the criteria is $\mathrm{C}_{2} \mathrm{P} \mathrm{C}_{3} \mathrm{P} \mathrm{C}_{1} \mathrm{P} \mathrm{C}_{6} \mathrm{I}$ $\mathrm{C}_{7} \mathrm{P}_{4} \mathrm{I}_{5} \mathrm{C}_{5} \mathrm{P}_{8}$ which indicates that required floor space $\left(\mathrm{C}_{2}\right)$ is the most preferred criterion and quality improvement $\left(\mathrm{C}_{8}\right)$ is the least important criterion. Then for each criterion, a weak order of the alternatives is determined, as shown in Table 12. Now, based on step (3) of sub-section 2.4, the Besson ranking of all the FMS selection criteria and also the Besson ranking of the considered FMS alternatives are determined, as given in Tables 13 and 14 respectively. Now, applying Eq. (26), the corresponding projection distances are computed, as shown in Table 15. From this table, the rankings of the projections or global ranks are obtained, as given in Table 16. In the last step of this method, the mean ranks of FMS alternatives are obtained from which the final ranking of the candidate alternatives is derived, as shown in Table 17. From this table, the ranking of FMS alternatives is observed as 7-2-14-6-8-5-3. FMS 3 is the best choice and FMS 6 is the worst chosen alternative.

Table 12

Weak order of the alternatives for each criterion in ORESTE method

\begin{tabular}{cc}
\hline Criteria & Weak order of alternatives \\
\hline $\mathrm{C}_{1}$ & 2 P 7 P 5 P 8 P 1 P 3 P 4 P 6 \\
$\mathrm{C}_{2}$ & 3 P 4 P 8 P 5 P 2 P 1 P 7 P 6 \\
$\mathrm{C}_{3}$ & 3 P 8 P 2 I 7 P 1 P 5 P 4 P 6 \\
$\mathrm{C}_{4}$ & 3 I6 P 1 I 2 I 4 P 7 I 8 P 5 \\
$\mathrm{C}_{5}$ & 6 I 8 P 2 I 3 I 5 P 1 I 4 P 7 \\
$\mathrm{C}_{6}$ & 8 P 1 I 3 I 5 P 2 I 4 I 6 P 7 \\
$\mathrm{C}_{7}$ & 2 P 3 I 4 I 7 P 1 I 6 I 8 P 5 \\
$\mathrm{C}_{8}$ & 4 I 7 P 3 I 5 2 I 6 I 8 P 1 \\
\hline
\end{tabular}

Table 13

Besson ranking of criteria in ORESTE method

\begin{tabular}{ccccccccc}
\hline Criteria & $\mathrm{C}_{1}$ & $\mathrm{C}_{2}$ & $\mathrm{C}_{3}$ & $\mathrm{C}_{4}$ & $\mathrm{C}_{5}$ & $\mathrm{C}_{6}$ & $\mathrm{C}_{7}$ & $\mathrm{C}_{8}$ \\
\hline Besson ranking & 3 & 1 & 2 & 6.5 & 6.5 & 4.5 & 4.5 & 8 \\
\hline
\end{tabular}

Table 14

Besson ranking of the alternatives in ORESTE method

\begin{tabular}{ccccccccc}
\hline Criteria & FMS1 & FMS2 & FMS3 & FMS4 & FMS5 & FMS6 & FMS7 & FMS8 \\
\hline $\mathrm{C}_{1}$ & 5 & 1 & 6 & 7 & 3 & 8 & 2 & 4 \\
$\mathrm{C}_{2}$ & 6 & 5 & 1 & 2 & 4 & 8 & 3 & 7 \\
$\mathrm{C}_{3}$ & 5 & 3.5 & 1 & 7 & 6 & 8 & 3.5 & 2 \\
$\mathrm{C}_{4}$ & 4 & 4 & 1.5 & 4 & 8 & 1.5 & 6.5 & 6.5 \\
$\mathrm{C}_{5}$ & 6.5 & 4 & 4 & 6.5 & 4 & 1.5 & 8 & 1.5 \\
$\mathrm{C}_{6}$ & 3 & 6 & 3 & 6 & 3 & 6 & 8 & 1 \\
$\mathrm{C}_{7}$ & 6 & 1 & 3 & 3 & 8 & 6 & 3 \\
$\mathrm{C}_{8}$ & 8 & 5 & 5 & 1.5 & 5 & 5 & 1.5 & 5 \\
\hline
\end{tabular}

Table 15

Projection distances of FMS alternatives in ORESTE method

\begin{tabular}{ccccccccc}
\hline Criteria & FMS1 & FMS2 & FMS3 & FMS4 & FMS5 & FMS6 & FMS7 & FMS8 \\
\hline $\mathrm{C}_{1}$ & 4 & 2 & 4.5 & 5 & 3 & 5.5 & 2.5 & 3.5 \\
$\mathrm{C}_{2}$ & 3.5 & 3 & 1 & 1.5 & 2.5 & 4.5 & 4 & 2 \\
$\mathrm{C}_{3}$ & 3.5 & 1.5 & 1.5 & 4.5 & 4 & 5 & 2.75 & 2 \\
$\mathrm{C}_{4}$ & 5.25 & 5.25 & 4 & 5.25 & 7.25 & 4 & 6.5 & 6.5 \\
$\mathrm{C}_{5}$ & 6.5 & 5.25 & 5.25 & 6.5 & 5.25 & 4 & 7.25 & 4 \\
$\mathrm{C}_{6}$ & 3.75 & 5.25 & 3.75 & 5.25 & 3.75 & 5.25 & 6.25 & 2.75 \\
$\mathrm{C}_{7}$ & 5.25 & 2.75 & 3.75 & 3.75 & 6.25 & 5.25 & 3.75 & 5.25 \\
$\mathrm{C}_{8}$ & 8 & 6.5 & 6.5 & 4.75 & 6.5 & 6.5 & 4.75 & 6.5 \\
\hline
\end{tabular}


Table 16

Mean global Besson rankings of the projections in ORESTE method

\begin{tabular}{ccccccccc}
\hline Criteria & FMS1 & FMS2 & FMS3 & FMS4 & FMS5 & FMS6 & FMS7 & FMS8 \\
\hline $\mathrm{C}_{1}$ & 27 & 6 & 32 & 36.5 & 13.5 & 50 & 8.5 & 16 \\
$\mathrm{C}_{2}$ & 16 & 13.5 & 1 & 3 & 8.5 & 32 & 27 & 6 \\
$\mathrm{C}_{3}$ & 16 & 3 & 3 & 32 & 27 & 36.5 & 11 & 6 \\
$\mathrm{C}_{4}$ & 43.5 & 43.5 & 27 & 43.5 & 62.5 & 27 & 57 & 57 \\
$\mathrm{C}_{5}$ & 57 & 43.5 & 43.5 & 57 & 43.5 & 27 & 62.5 & 27 \\
$\mathrm{C}_{6}$ & 20.5 & 43.5 & 20.5 & 43.5 & 20.5 & 43.5 & 51.5 & 11 \\
$\mathrm{C}_{7}$ & 43.5 & 11 & 20.5 & 20.5 & 51.5 & 43.5 & 20.5 & 43.5 \\
$\mathrm{C}_{8}$ & 64 & 57 & 57 & 34.5 & 57 & 57 & 34.5 & 57 \\
\hline
\end{tabular}

Table 17

Mean and overall ranks in ORESTE method

\begin{tabular}{ccccccccc}
\hline FMS & 1 & 2 & 3 & 4 & 5 & 6 & 7 & 8 \\
\hline Mean rank & 287.5 & 221 & 204.5 & 270.5 & 284 & 316.5 & 272.5 & 223.5 \\
Rank & 7 & 2 & 1 & 4 & 6 & 8 & 5 & 3 \\
\hline
\end{tabular}

\subsection{OCRA method}

At first, using Eq. (28), the aggregate performance of the alternatives with respect to all the input criteria is calculated. Then based on these values, the linear preference ratings for the input criteria are computed. Applying Eq. (30), the aggregate performance of the alternatives on all the beneficial or output criteria are then determined and subsequently, the linear preference ratings for the output criteria are calculated. Lastly, using Eq. (32), the overall preference rating for each of the FMS alternative is determined. The detailed computations of this method are illustrated in Table 18. In this method, the ranking of FMS alternatives is obtained as 6-3-1-4-7-5-8-2, which suggests that FMS 3 attains the top rank. FMS 8 is the second best choice and FMS 7 has the last rank.

Table 18

Computation details for OCRA method

\begin{tabular}{ccccccc}
\hline FMS & $\overline{\mathrm{I}_{\mathrm{i}}}$ & $\overline{\overline{\mathrm{I}_{i}}}$ & $\overline{\mathrm{O}_{\mathrm{i}}}$ & $\overline{\overline{\mathrm{O}_{i}}}$ & $\mathrm{P}_{\mathrm{i}}$ & $\mathrm{Rank}$ \\
\hline 1 & 0.2458 & 0.2458 & 0.9466 & 0.0696 & 0.0677 & 6 \\
2 & 0.3003 & 0.3003 & 1.3558 & 0.4788 & 0.5314 & 3 \\
3 & 0.3078 & 0.3078 & 1.5881 & 0.7111 & 0.7712 & 1 \\
4 & 0.1280 & 0.1280 & 1.3492 & 0.4722 & 0.3525 & 4 \\
5 & 0.2555 & 0.2555 & 0.8792 & 0.0022 & 0.0100 & 7 \\
6 & 0 & 0 & 1.3515 & 0.4745 & 0.2269 & 5 \\
7 & 0.2477 & 0.2477 & 0.8770 & 0.0000 & 0 & 8 \\
8 & 0.3030 & 0.3030 & 1.3558 & 0.4788 & 0.5341 & 2 \\
\hline
\end{tabular}

\subsection{ARAS method}

From the weighted normalized decision matrix, as given in Table 19, and using Eq. (35), the optimality function $\left(\mathrm{S}_{\mathrm{i}}\right)$ for each of the FMS alternative is calculated. Then the corresponding values of the utility degree $\left(U_{i}\right)$ are determined for all the alternatives. The values of $S_{i}$ and $U_{i}$, and the ranking achieved by the FMS alternatives are exhibited in Table 20. It is revealed from this table that FMS 3 is the best chosen alternative and FMS 5 obtains the last rank. FMS 2 has the second rank. 
Table 19

Weighted normalized decision matrix for ARAS method

\begin{tabular}{ccccccccc}
\hline FMS & COS & RFS & WIP & PF & VF & EF & LTR & QI \\
\hline 1 & 0.0177 & 0.0165 & 0.0171 & 0.0161 & 0.0115 & 0.0178 & 0.0127 & 0.0047 \\
2 & 0.0216 & 0.0168 & 0.0194 & 0.0161 & 0.0161 & 0.0127 & 0.0229 & 0.0117 \\
3 & 0.0134 & 0.0244 & 0.0224 & 0.0207 & 0.0161 & 0.0178 & 0.0178 & 0.0164 \\
4 & 0.0105 & 0.0208 & 0.0133 & 0.0161 & 0.0115 & 0.0127 & 0.0178 & 0.0211 \\
5 & 0.0186 & 0.0173 & 0.0163 & 0.0046 & 0.0161 & 0.0178 & 0.0051 & 0.0164 \\
6 & 0.0100 & 0.0133 & 0.0122 & 0.0207 & 0.0207 & 0.0127 & 0.0127 & 0.0117 \\
7 & 0.0197 & 0.0140 & 0.0194 & 0.0115 & 0.0046 & 0.0051 & 0.0178 & 0.0211 \\
8 & 0.0181 & 0.0189 & 0.0199 & 0.0115 & 0.0207 & 0.0229 & 0.0127 & 0.0117 \\
\hline
\end{tabular}

Table 20

$\mathrm{S}_{\mathrm{i}}$ and $\mathrm{U}_{\mathrm{i}}$ values in ARAS method

\begin{tabular}{cccc}
\hline FMS & $\mathrm{S}_{\mathrm{i}}$ & $\mathrm{U}_{\mathrm{i}}$ & Rank \\
\hline 1 & 0.1140 & 0.7647 & 6 \\
2 & 0.1373 & 0.9209 & 2 \\
3 & 0.1491 & 1.0000 & 1 \\
4 & 0.1237 & 0.8302 & 4 \\
5 & 0.1122 & 0.7530 & 8 \\
6 & 0.1140 & 0.7649 & 5 \\
7 & 0.1132 & 0.7597 & 7 \\
8 & 0.1364 & 0.9153 & 3 \\
\hline
\end{tabular}

\section{Comparative analysis}

In order to validate the applicability and suitability of the six considered preference ranking methods to solve this FMS selection problem, their relative ranking performance is compared using the following measures:

(a) Spearman's rank correlation coefficient,

(b) Kendall's coefficient of concordance,

(c) agreement between the top three ranked alternatives, and

(d) number of ranks matched, as the percentage of the number of considered alternatives.

Using Spearman's rank correlation coefficient $\left(r_{s}\right)$ value, the similarity between two sets of rankings can be measured. Usually, its value lies between -1 and +1 , where the value of +1 denotes a perfect match between two rank orderings. Table 21 shows the Spearman's rank correlation coefficients when the rankings of FMS alternatives as obtained using all the six preference ranking methods are compared between themselves and also with respect to the rank ordering as derived by Karsak (Karsak, 2002). It is observed that the $r_{s}$ value ranges between 0.5238 and 0.9761 . The performance of ORESTE method is satisfactory with respect to $r_{s}$ value. Other methods, except COPRAS and ARAS, also perform well. It is also observed that CORRAS is almost similar to OCRA, and OCRA to ARAS.

The relative performance of these methods with respect to the ranking of FMS alternatives as obtained by Karsak (2002) is well visualized using the value of Z, which can be expressed as below:

$$
\mathrm{Z}=\mathrm{r}_{\mathrm{s}} \sqrt{\mathrm{m}-1}
$$

Fig. 1 plots the $\mathrm{Z}$ values for all the considered preference ranking methods and it reveals that ORESTE is the best method. On the other hand, the performance of OCRA and ARAS methods are not so much satisfactory. 


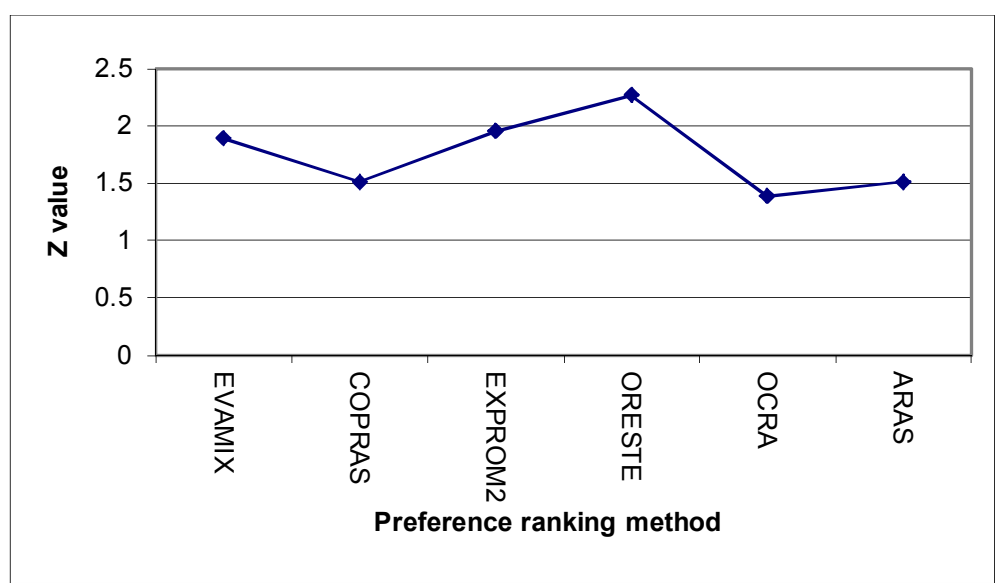

Fig. 1. $\mathrm{Z}$ values for the six preference ranking methods

The similarity of rankings obtained by these methods is also measured using Kendall's coefficient of concordance (z). Its value lies between 0 and 1 , where a value of 1 results in a perfect match. In this case, the value of $\mathrm{z}$ is computed as 0.8705 , which suggests that there is an almost perfect agreement between the considered methods. When the ranking of FMS alternatives as derived by Karsak (2002) is taken into consideration, the $\mathrm{z}$ value is observed to be 0.8318 , which is also quite high suggesting a similarity of the rank orderings between those obtained by the six preference ranking methods and that of Karsak (2002). A high z value signifies the suitability of these methods to solve the considered FMS selection problem.

Sometimes, the decision maker may be interested to select the best FMS as the single choice. So, another test is performed based on the agreement between the top three ranked FMS alternatives. Here, a result of $(1,2,3)$ means the first, second and third ranks match; $(1,2, \#)$ means the first and second ranks match; $(1, \#, \#)$ means only the first ranks match; and (\#,\#,\#) means no match. Table 21 shows the results of this test, which indicates that ARAS method has the maximum number of mismatches with respect to the ranking of the top three FMS alternatives. It is also quite interesting to note that for all the methods, the top ranked alternative is FMS 3.

Table 21

A comparative study on ranking performance for six preference ranking methods

\begin{tabular}{|c|c|c|c|c|c|c|}
\hline Method & EVAMIX & COPRAS & EXPROM2 & ORESTE & OCRA & ARAS \\
\hline Karsak & $0.7142,(1, \#, \#), 12.5$ & $0.5714,(1, \#, \#), 12.5$ & $0.7380,(1, \#, \#), 25$ & $0.8571,(1,2,3), 50$ & $0.5238,(1, \#, \#), 25$ & $0.5714,(1,2,3), 50$ \\
\hline EVAMIX & & $0.7619,(1,2,3), 37.5$ & $0.7857,(1,2,3), 37.5$ & $0.8095,(1, \#, \#), 12.5$ & $0.8095,(1,2,3), 37.5$ & $0.7142,(1, \#, \#), 25$ \\
\hline COPRAS & & & $0.9285,(1,2,3), 62.5$ & $0.7619,(1, \#, \#), 25$ & $0.9761,(1,2,3), 75$ & $0.9285,(1, \#, \#), 25$ \\
\hline EXPROM2 & & & & $0.8809,(1, \#, \#), 50$ & $0.8571,(1,2,3), 50$ & $0.8095,(1, \#, \#) 37.5$ \\
\hline ORESTE & & & & & $0.7380,(1, \#, \#), 25$ & $0.7857,(1,2,3), 50$ \\
\hline OCRA & & & & & & $0.9523,(1, \#, \#), 50$ \\
\hline
\end{tabular}

Table 22

Characteristics of the six preference ranking methods

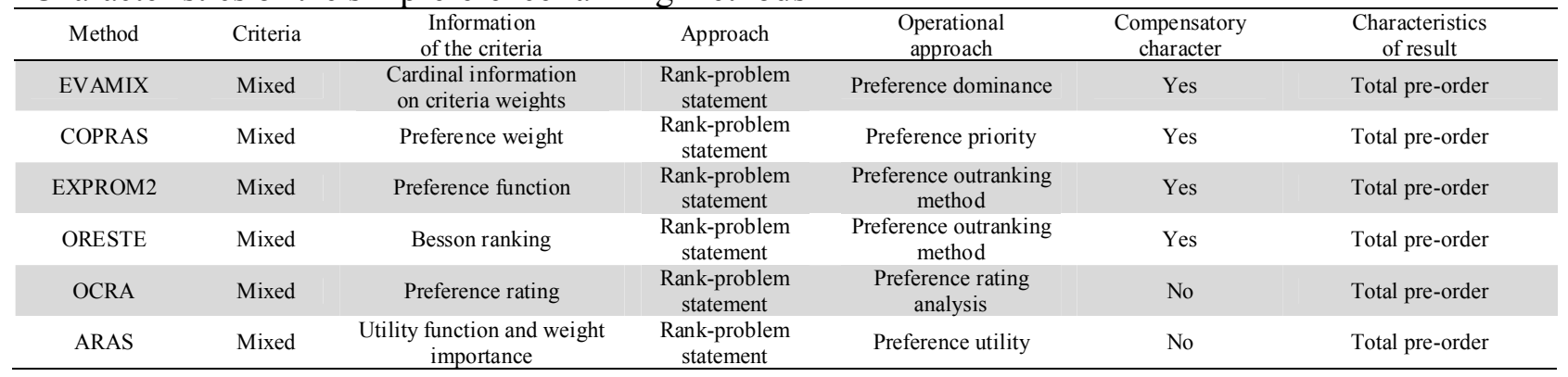


The last test is performed with respect to the number of ranks matched, expressed as the percentage of the number of alternatives considered. These results are also shown in Table 21. In this test, it is observed that ORESTE emerges out as the best preference ranking method. Table 22 exhibits various characteristics of the six considered preference ranking methods (Teghem et al., 1989). It is observed that all these methods are quite capable to deal with both the cardinal and ordinal data, and can provide the total ranking of the considered alternatives, although they have different mathematical treatments and operational approaches.

\section{Results and discussions}

In order to validate the superiority of ORESTE method over the other considered preference ranking methods, two more FMS selection problems are studied. The first problem (Rao and Parnichkun, 2009) considers selection of an FMS from a set of eight alternatives which are evaluated based on seven criteria, i.e. reduction in labour cost (\%), reduction in WIP (\%), reduction in set up cost (\%), increase in market response, increase in quality, capital and maintenance cost (\$000), and floor space used (sq. ft.). While solving this problem using digraph and matrix approach, Rao and Parnichkun (2009) derived a ranking of FMS alternatives as 3-4-7-2-5-6-1-8. FMS 7 was the best alternative and FMS 8 was the worst choice. The same FMS selection problem is now solved employing the six preference ranking methods and their relative ranking performance is shown in Table 23. From this table, it is found that there exists a perfect match between the rank ordering as obtained by ORESTE method and that derived by Rao and Parnichkun (2009). The Kendal's coefficient of concordance value is also estimated to be quite high $(\mathrm{z}=0.9553)$ which indicates the existence of a near to perfect agreement between the considered methods.

Table 23

Performance test results of six preference ranking methods for example 2

\begin{tabular}{|c|c|c|c|c|c|c|}
\hline Method & EVAMIX & COPRAS & EXPROM2 & ORESTE & OCRA & ARAS \\
\hline Rao and Parnichkun & $0.8810,(\#, \#, \#), 12.5$ & $0.9524,(\#, \#, 3), 50$ & $0.9048,(1,2, \#), 37.5$ & $1.0000,(1,2,3), 100$ & $0.9762,(\#, \#, 3), 62.5$ & $0.9524,(\#, \#, 3), 50$ \\
\hline EVAMIX & & $0.9524,(1, \#, \#), 50$ & $0.8810,(\#, \#, \#), 50$ & $0.8810,(\#, \#, \#), 12.5$ & $0.9286,(1, \#, \#), 25$ & $0.9524,(1, \#, \#), 50$ \\
\hline COPRAS & & & $0.9286,(\#, \#, \#), 25$ & $0.9524,(\#, \#, 3), 50$ & $0.9762,(1,2,3), 75$ & $1.0000,(1,2,3), 100$ \\
\hline EXPROM2 & & & & $0.9048,(1,2, \#), 37.5$ & $0.8810,(\#, \#, \#), 12.5$ & $0.9286,(\#, \#, \#), 25$ \\
\hline ORESTE & & & & & $0.9762,(\#, \#, 3), 75$ & $0.9524,(\#, \#, 3), 50$ \\
\hline OCRA & & & & & & $0.9762,(1,2,3), 75$ \\
\hline
\end{tabular}

Rao and Parnichkun (2009) also cited another FMS selection problem which consists of four FMS alternatives and six evaluation criteria, and solved that problem using digraph and matrix approach to obtain a comparative ranking of FMS alternatives as 2-1-3-4. The six considered criteria are annual depreciation and maintenance costs, quality of results, ease of use, competitiveness, adaptability and expandability. When this FMS selection problem is solved using the six preference ranking methods, their comparative ranking performance is derived as shown in Table 24 . A very high $\mathrm{z}$ value $(\mathrm{z}=$ 0.9778) assures the applicability of these preference ranking methods to solve this FMS selection problem too. From Tables 23 and 24, it becomes quite clear that ORESTE method provides the exact rank orderings of FMS alternatives when compared to those obtained by Rao and Parnichkun (2009). It can be concluded that ORESTE method outperforms the other methods with respect to their ranking performance.

\section{Table 24}

Performance test results of six preference ranking methods for example 3

\begin{tabular}{|c|c|c|c|c|c|c|}
\hline Method & EVAMIX & COPRAS & EXPROM2 & ORESTE & OCRA & ARAS \\
\hline Rao and Parnichkun & $0.4000,(1, \#, \#), 25$ & $0.4000,(1, \#, \#), 25$ & $1.0000,(1,2,3), 100$ & $1.0000,(1,2,3), 100$ & $0.2000,(1, \#, \#), 50$ & $1.0000,(1,2,3), 100$ \\
\hline EVAMIX & & $1.0000,(1,2,3), 100$ & $0.4000,(1, \#, \#), 25$ & $0.4000,(1, \#, \#), 25$ & $0.8000,(1,2, \#), 50$ & $0.4000,(1, \#, \#), 25$ \\
\hline COPRAS & & & $0.4000,(1, \#, \#), 25$ & $0.4000,(1, \#, \#), 25$ & $0.8000,(1,2, \#), 50$ & $0.4000,(1, \#, \#), 25$ \\
\hline EXPROM2 & & & & $1.0000,(1,2,3), 100$ & $0.2000,(1, \#, \#), 25$ & $1.0000,(1,2,3), 100$ \\
\hline ORESTE & & & & & $0.2000,(1, \#, \#), 25$ & $1.0000,(1,2,3), 100$ \\
\hline OCRA & & & & & & $0.2000,(1, \#, \#), 25$ \\
\hline
\end{tabular}




\section{Mapping to industrial problems}

The main aim of this paper is to investigate the efficacy of different state-of-the-art preference ranking methods for arriving at the best FMS selection decision. The performance of six preference ranking methods is compared with respect to their suitability to solve MCDM problems, simplicity of use, consistency of choice and degree of decision maker's involvement. As discussed earlier, most of these methods need the definition of criteria weights, which express the relative importance of one criterion over the other. This is one of the most decisive phases for executing any preference ranking-based MCDM method.

Application of EVAMIX method starts with the initial decision matrix. A linear normalization technique is adopted to convert all the criteria values into dimensionless numbers ranging from 0 to 1 . This is required to compare all the non-commensurable units in the decision matrix. After normalization, the dominance scores for each pair of alternatives are calculated on a criterion-bycriterion comparison basis and an additive interval model is then adopted followed by a weighted summation method. For COPRAS and ARAS methods, a simple weighted summation technique is separately adopted for the normalized beneficial and non-beneficial attributes, leading to the calculation of an overall significance or utility for each of the alternatives. The main difference between the operational procedures of COPRAS and ARAS methods lies in how they normalize the original decision matrix. In COPRAS method, a straightforward linear normalization procedure is used, whereas in ARAS method, a two-step linear normalization technique is adopted. EXPROM2 method is based on the comparison of alternatives considering the deviations that the alternatives show for each criterion. It allows direct computation on the normalized variables on the basis of a 'usual criterion', which is the simplest preference function, requiring no intervention from the decision maker. It also allows the involvement of different preference models to each criterion, each one being characterized by a certain degree of intricacy and a given involvement of some preference parameters to be set by the decision maker. Application of ORESTE method starts with defining a weak order of criteria indicating their relative importance. Then, the alternatives are compared on the basis of Besson rankings and finally, global mean ranks for the alternatives are obtained. This procedure is just like an aggregation technique as followed in most of the popular preference ranking methods. Lastly, application of OCRA method starts with the calculation of preference ratings for each alternative with respect to all the beneficial and non-beneficial criteria. This same concept is also used for COPRAS and ARAS methods. Finally, an aggregation technique is adopted to determine the overall preference rating of each alternative showing the ranking of the alternatives. Thus, it can be said that although the mathematical and operational procedures of the considered preference ranking methods substantially differ from each other, but there are similarities in the concepts they use to reach the final evaluation and ranking of the alternatives in terms of overall utility or significance or preference rating. Hence, mapping an industrial example (like FMS selection) to different preference ranking methods will not be quite troublesome.

\section{Conclusions}

Although different MCDM methods have already been proposed by the past researchers to address the issue of FMS evaluation and selection, it is still not clear which MCDM method is the best for a given FMS selection problem. This paper considers six potential preference ranking-based methods and compares their ranking performance while selecting an FMS for a specific industrial application. Four performance tests are conducted for this ranking performance comparison and also for measuring the degree of agreement between the rankings derived by the considered methods. It is found that although ORESTE performs well, any preference ranking method can be successfully applied for FMS selection problems as the change of the method does not produce any difference in the top ranked FMS alternative. The main reason behind it is that although these methods are based on different mathematical models, they either consider formulation of dominance scores of alternatives on criterion- 
by-criterion basis (as in EVAMIX method) or defining relative priorities of alternatives based on weighted normalized decision matrix (as in COPRAS method) or defining some preference functions (as in EXPROM2 method) or calculating preference ratings of the alternatives considering all the selection criteria (as in OCRA method) or determining optimality functions (as in ARAS method), ultimately leading to the development of a ranking score, which is nothing but an aggregation of all the weighted normalized criteria and a balance between total and individual satisfaction or preference. So basically, all these methods whether they adopt preference function or weighted sum utility value, indicate how much an alternative is preferred to other alternatives. The minor discrepancy that appears between the intermediate rankings obtained by different methods can be attributed to the difference in their mathematical and operational approaches to select the best alternative, the way of dealing with criteria weights in their calculations and introduction of additional parameters affecting the final ranking of the alternatives. In few cases where strong disagreement between these methods occurs, it is due to presence of mixed ordinal-cardinal data in the decision matrix. Thus, the focus would lie not on the selection of the most appropriate preference ranking method to be adopted, but on proper structuring of the decision problem considering relevant criteria and decision alternatives. Future scope may include the application of other preference ranking methods, like COPRAS-G, PSI (preference selection index) etc. to solve complex decision-making problems with crisp, grey and fuzzy criteria.

\section{References}

Bayazit, O. (2005). Use of AHP in decision-making for flexible manufacturing systems. Journal of Manufacturing Technology and Management, 16(7), 808-819.

Bhattacharya, A., Abraham, A., Vasant, P., \& Grosan, C. (2007). Evolutionary artificial neural network for selecting flexible manufacturing systems under disparate level-of-satisfaction of decision maker. International Journal of Innovative Computing, Information and Control, 3(1), 131-140.

Borenstein, D. (1998). A visual interactive multicriteria decision analysis model for FMS design. International Journal of Advanced Manufacturing Technology, 14(11), 848-857.

Chan, F.T.S., Jiang, B., \& Tang, N.K.H. (2000). The development of intelligent decision support tools to aid the design of flexible manufacturing systems. International Journal of Production Economics, 65(1), 73-84.

Doumpos, M., \& Zopounidis, C. (2004). A multi-criteria classification approach based on pair-wise comparison. European Journal of Operational Research, 158(2), 378-389.

Hajkowicz, S., \& Higgins, A. (2008). A comparison of multiple criteria analysis techniques for water resource management. European Journal of Operational Research, 184(1), 255-265.

Kaklauskas, A., Zavadskas, E.K., Raslanas, S., Ginevicius, R., Komka, A., \& Malinauskas, P. (2006). Selection of low e-windows in retrofit of public buildings by applying multiple criteria method COPRAS: A Lithuanian case. Energy and Buildings, 38(5), 454-462.

Kaklauskas, A., Zavadskas, E.K., \& Trinkunas, V. (2007). A multiple criteria decision support on-line system for construction. Engineering Applications of Artificial Intelligence, 20(2), 163-175.

Karsak, E.E., \& Tolga, E. (2001). Fuzzy multi-criteria decision-making procedure for evaluating advanced manufacturing system investments. International Journal of Production Economics, 69(1), 49-64.

Karsak, E.E., \& Kuzgunkaya, O. (2002). A fuzzy multiple objective programming approach for the selection of a flexible manufacturing system. International Journal of Production Economics, 79(2), 101-111.

Karsak, E.E. (2002). Distance-based fuzzy MCDM approach for evaluating flexible manufacturing system alternatives. International Journal of Production Research, 40(13), 3167-3181.

Karsak, E.E. (2008). Using data envelopment analysis for evaluating flexible manufacturing systems in the presence of imprecise data. International Journal of Advanced Manufacturing Technology, 35(910), 867-874.

Kulak, O., \& Kahraman, C. (2005). Multi-attribute comparison of advanced manufacturing systems using fuzzy vs. crisp axiomatic design approach. International Journal of Production Economics, 95(3), 415-424. 
Liu, S-T. (2008). A fuzzy DEA/AR approach to the selection of flexible manufacturing systems. Computers \& Industrial Engineering, 54(1), 66-76.

Lotfi, V. (1995). Implementing flexible automation: A multiple criteria decision making approach. International Journal of Production Economics, 38(2-3), 255-268.

Martel, J.M., \& Matarazzo, B. (2005). Other outranking approaches. In: Figueira J, Salvatore G, Ehrgott M. (Eds.) Multiple Criteria Decision Analysis: State of the Art Surveys. Springer: New York.

Mehrabad, M.S., \& Anvari, M. (2010). Provident decision making by considering dynamic and fuzzy environment for FMS evaluation. International Journal of Production Research, 48(15), 4555-4584.

O'Grady, P.J., \& Menon, U. (1986). A concise review of flexible manufacturing systems and FMS literature. Computers in Industry, 7(2), 155-167.

Ovchinnikov, S., \& Roubens, M. (1992). On fuzzy strict preference, indifference, and incomparability relations. Fuzzy Sets and Systems, 49(1), 15-20.

Pastijn, H., \& Leysen, J. (1989). Constructing an outranking relation with ORESTE. Mathematical and Computer Modelling, 12(10-11), 1255-1268.

Parkan, C., \& Wu, M-L. (1997). On the equivalence of operational performance measurement and multiple attribute decision making. International Journal of Production Research, 35(11), 2963-2988.

Parkan, C., \& Wu, M-L. (2000). Comparison of three modern multicriteria decision-making tools. International Journal of Systems Science, 31(4), 497-517.

Raju, K.S., \& Kumar, D.N. (1999). Multicriterion decision making in irrigation planning. Agricultural Systems, 62(2), 117-129.

Rao, R.V. (2006). A decision-making framework model for evaluating flexible manufacturing systems using digraph and matrix methods. International Journal of Advanced Manufacturing Technology, 30(11-12), 1101-1110.

Rao, R.V. (2008). Evaluating flexible manufacturing systems using a combined multiple attribute decision making method. International Journal of Production Research, 46(7), 1975-1989.

Rao, R.V., \& Parnichkun, M. (2009). Flexible manufacturing system selection using a combinatorial mathematics-based decision-making method. International Journal of Production Research, 47(24), 6981-6998.

Rao, R.V. (2009). Flexible manufacturing system selection using an improved compromise ranking method. International Journal of Industrial and System Engineering, 4(2), 198-215.

Rao, R.V., \& Singh, D. (2011). Evaluating flexible manufacturing systems using Euclidean distancebased integrated approach. International Journal of Decision Sciences, Risk and Management, 3(12), 32-53.

Roubens, M. (1982). Preference relations on actions and criteria in multicriteria decision making. European Journal of Operational Research, 10(1), 51-55.

Sarkis, J. (1997). Evaluating flexible manufacturing systems alternatives using data envelopment analysis. The Engineering Economist, 43(1), 25-47.

Shang, J., \& Sueyoshi, T. (1995). A unified framework for the selection of a flexible manufacturing system. European Journal of Operational Research, 85(2), 297-315.

Talluri, S., Whiteside, M.M., \& Seipel, S.J. (2000). A nonparametric stochastic procedure for FMS evaluation. European Journal of Operational Research, 124(3), 529-538.

Teghem, J., Delhaye, C., \& Kunsch, P.L. (1989). An interactive decision support system (IDSS) for multicriteria decision aid. Mathematical and Computer Modelling, 12(10-11), 1311-1320

Turskis, Z., \& Zavadskas, E.K. (2010). A novel method for multiple criteria analysis: Grey additive ratio assessment (ARAS-G) method. Informatica, 21(4), 597-610.

Wabalackis, R.N. (1988). Justification of FMS with the analytic hierarchy process. Journal of Manufacturing Systems, 7(3), 175-182.

Zavadskas, E.K., Kaklauskas, A., Turskis, Z., \& Tamošaitienè, J. (2008). Selection of the effective dwelling house walls by applying attributes values determined at intervals. Journal of Civil Engineering \& Management, 14(2), 85-93.

Zavadskas, E.K., \& Turskis, Z. (2010). A new additive ratio assessment (ARAS) method in multicriteria decision-making. Technological and Economic Development of Economy, 16(2), 159-172. 